\title{
SENSITIVITY ANALYSIS OF EFFICIENCY AND MALMQUIST PRODUCTIVITY INDICES: AN APPLICATION TO SPANISH SAVINGS BANKS
}

\section{Emili Tortosa-Ausina, Emili Grifell-Tatjé, Carmen Armero and David Conesa}

WP-EC 2002-30

Correspondence to: Emilio Tortosa-Ausina, Departament d'Economia, Universitat Jaume I, Campus del Riu Sec, 12071 CASTELLON, Spain, Tel. +34 9647286 06, Fax +34 9647285 91, e-mail: tortosa@uji.es

Editor: Instituto Valenciano de Investigaciones Económicas, S.A.

Primera Edición Noviembre 2002

Depósito Legal: V-4548-2002

IVIE working papers offer in advance the results of economic research under way in order to encourage a discussion process before sending them to scientific journals for their final publication.

\footnotetext{
* We would like to thank George E. Battese, Kevin J. Fox, Quentin Grafton, Joseph G. Hirschberg and other participants at the Economic Measurement Group '02 Workshop held at the School of Economics of the University of New South Wales for helpful comments. Financial support from the Instituto Valenciano de Investigaciones Económicas (IVIE) is also gratefully acknowledged.

** E. Tortosa: Universitat Jaume I; E. Grifell: Universitat Autónoma de Barcelona ; C. Armero and D. Conesa: Universitat de Valencia.
} 


\title{
SENSITIVITY ANALYSIS OF EFFIGIENGY AND MALMQUIST PRODUCTIVITY INDIGES: AN APPLICATION TO SPANISH SAVINGS BANKS
}

\author{
Emili Tortosa-Ausina, Emili Grifell-Tatjé, Garmen Armero and David Gonesa
}

\begin{abstract}
Hypothesis testing and statistical precision in the context of nonparametric efficiency and productivity measurement have been investigated since the early 1990s. Recent contributions focus on this matter through the use of resampling methods - i.e., bootstrapping techniques. However, empirical evidence is still practically non-existent. This gap is more noticeable in the case of banking efficiency studies, where the literature is immense. In this paper, we explore productivity growth and productive efficiency for Spanish savings banks over the (initial) postderegulation period 1992-1998 using Data Envelopment Analysis (DEA) and bootstrapping techniques. Results show that productivity growth has occurred, mainly due to improvement in production possibilities, and that mean efficiency has remained fairly constant over time. The bootstrap analysis yields further evidence, as for many firms productivity growth, or decline, is not statistically significant. With regard to efficiency measurement, the bootstrap reveals that the disparities in the original efficiency scores of some firms are lessened to a great extent.
\end{abstract}

Keywords: bootstrap, data envelopment analysis, efficiency, productivity, savings bank

JEL Classification: C14, C30, C61, G21, L5

\section{RESUMEN}

Desde principios de los años noventa ha habido avances notables en el contraste de hipótesis dentro del contexto de la medición de la eficiencia y la productividad mediante técnicas paramétricas. Las contribuciones más recientes han enfocado el tema a través de métodos de remuestreo -conocidos en la literatura como técnicas bootstrap-. Sin embargo, prácticamente no ha habido aplicaciones, algo también patente en el estudio de la eficiencia de la empresa bancaria. En este artículo, analizamos la eficiencia productiva y el crecimiento de la productividad de las cajas de ahorro españolas durante el periodo 1992-1998 a través de técnicas no paramétricas (DEA) y de técnicas bootstrap, con el fin de poder realizar inferencia estadística. Los resultados indican que la productividad ha aumentado, principalmente debido a una mejora en las posibilidades de producción, mientras que la eficiencia promedio no ha variado sustancialmente. El análisis bootstrap revela que, en el caso de la productividad, para muchas empresas su aumento o disminución no es estadísticamente significativo. En cuanto a la eficiencia, muestra que las diferencias entre empresas individuales se reducen de manera notable cuando consideramos intervalos de confianza.

Palabras clave: bootstrap, técnicas no paramétricas, eficiencia, productividad, cajas de ahorro. 


\section{Introduction}

Over the last twenty years, the study of the efficiency of financial institutions has increased enormously, as revealed in the comprehensive survey by Berger and Humphrey (1997). Although the literature is still growing at a fast rate, their study covered 130 relevant studies that applied frontier efficiency analysis to this type of firms in 21 countries, using both parametric and nonparametric techniques to measure efficiency. Their attempts were manifold, and included directions for further research. Among these was suggested the issue of deriving confidence intervals for efficiency measures in order to compare them in a statistical sense. Specifically, they suggest that new research in the area of efficiency should try to provide confidence intervals for the efficiency estimates they generate.

This question is closely related to the long-standing debate on what technique should be chosen for efficiency measurement. Both parametric and nonparametric techniques have been widely used, and the consensus is that neither technique is better than the other, ${ }^{1}$ because of the trade-off they are affected by. Namely, parametric techniques have the advantage of allowing for random error; in contrast, they impose a particular functional form that presupposes the shape of the frontier. On the other hand, nonparametric techniques tend to envelope data more closely, but they do not allow for random error.

Data Envelopment Analysis (DEA) is one of the most widely used among the latter. This inability to allow for random error has induced many authors to label it as deterministic. However, recent literature has silenced "this tired refrain", as Lovell (2000) defines it. In particular, Simar and Wilson (1998, 1999a, 2000) define a statistical model which allows for the determination of the statistical properties of the nonparametric estimators in the multi-input and multi-output case.

The important practical implication of their findings is that statistical inference is possible. Hence, nonparametric methods to measure efficiency would keep their advantages, but would somehow allow for random error. For this, a computer-intensive approach is used: the bootstrap (Efron, 1979; Efron and Tibshirani, 1993; Horowitz, 1997, 2001a,b). It consists of resampling an original sample extensively, until an estimate of a statistic's sampling distribution is inductively arrived at. This estimated sampling distribution is then used to make population inferences. We should point out that previous attempts to provide statistical precision to DEA efficiency scores have been made, and were brilliantly surveyed by Grosskopf (1996). One of these, the approach suggested by Banker (1993, 1996), which made some assumptions on the Data Generating Process (DGP). In contrast, the bootstrap does not need to rely on asymptotic theory to estimate the distribution of a statistic. Instead, it is a resampling method which may be implemented much more easily due to the availability of modern computing power. As such, it has has become widely accepted as an econometric procedure and is easily implemented in standard software packages such as RATS, TSP, LIMDEP, SHAZAM, STATA, or S-PLUS.

It is therefore also important to judge the relevance of these methods in econometric terms. In every econometric study, a crucial issue is that of the statistical significance of the results achieved. When providing the results of a regression equation, it is often the case that we may well choose to stress the

\footnotetext{
${ }^{1}$ In fact, out of those 130 studies surveyed by Berger and Humphrey (1997), 69 were nonparametric.
} 
interval estimate over the point estimate. Until the appearance of early contributions on hypothesis testing in DEA which relied on asymptotic theory, or the most recent which rely on bootstrapping techniques, this was not possible when reporting on the results generated by nonparametric efficiency measurement techniques. $^{2}$ Now we can use these methods to test for statistical significance among differences in firms' efficiency scores, in much the same way that $t$ ratios are used in classical regression studies.

Banking in general, and the Spanish banking industry in particular, is a fascinating context in which to applying these instruments. It has been reshaped by the many changes that have taken place, such as deregulation, liberalization, and technological advances. Two type of firms largely dominate the industry, namely, private commercial banks and savings banks. The latter has been the most successful in gaining market. It was also subject to the tightest regulation, and hence, deregulation initiatives may have affected this group more profoundly. For these reasons, among others, they warrant our attention. Specifically, our attempt is to analyze the efficiency and productivity of Spanish savings banks over the 1992-1998 post-deregulation period, and provide statistical precision to our results using the sensitivity analysis in Simar and Wilson (1998).

This application is important for several reasons. Firstly, although Simar and Wilson's methodology is powerful, there is a lack of empirical applications which use their bootstrap techniques. ${ }^{3}$ Second, the study of the efficiency of financial institutions has hardly considered this topic, although it clearly provides a measure of statistical precision for DEA. One exception is the study by Ferrier and Hirschberg (1997), who attempted to allow for random error in DEA in an application with Italian banking data, which focused exclusively on efficiency. Another is the work of Gilbert and Wilson (1998), which examines the productivity angle. Third, we improve (very) slightly previous approaches to bootstrapping DEA results by applying a more hi-tech method for bandwidth selection - as we will deal with nonparametric estimation of efficiency scores' densities.

A number of studies have focused on the performance of Spanish savings banks during the deregulatory period. They vary a great deal in their conclusions, because of different techniques used to measure efficiency, different measures and definitions of inputs and outputs, different samples, or simply different attempts. However, on the statistical significance of efficiency differences, the empirical evidence still has to come.

Our attempts are not exclusively confined to conferring statistical precision to efficiency scores. Additionally, and complementarily, we analyze productivity change over the sample period. For this, we consider nonparametric techniques (Grosskopf, 1993) which again involve the estimation of productivity change which disregards statistical significance. Put other way, we do not know whether certain firm's productivity growth, or decline, is significantly different from one. Simar and Wilson (1999a) provide an appropriate tool to achieve this, which is different from that provided in Simar and Wilson (1998) for efficiency scores, but complementary.

In this case, the application to Spanish savings banks over the 1992-1998 period turns out to be even

\footnotetext{
${ }^{2}$ Other earlier attempts to use resampling in the general context of nonparametric efficiency measurement include Färe and Whittaker (1995), Färe et al. (1989), Grosskopf and Yaisawarng (1990), or Ferrier et al. (1993).

${ }^{3} \mathrm{~A}$ recent application, although in a very different setting, is that by González and Miles (2002).
} 
more interesting. The research studies focusing on these questions are thinner on the ground. Among these are studies by Pastor (1995) and Grifell-Tatjé and Lovell (1996), which analyze the productivity of savings banks, although the former extends the analysis to commercial banks. Our study complements theirs in several ways. Firstly, whilst they focus on the deregulation period (1987-1992 and 1986-1991, respectively) our work focuses on the post-deregulation period, ${ }^{4}$ in which the wave of merger and acquisitions (M\&As) had almost come to an end. Hence, from a dynamic point of view, it turns out to be a fascinating period to study, as we have nearly the same number of firms at every period. In addition, this constitutes an important prerequisite when measuring productivity change, as panel data are required. Furthermore, our output definition accounts for business lines in which savings banks might have specialized over the deregulation period. Yet analogously to what happens to efficiency scores, our main contribution consists of conferring statistical significance to the results. In addition, we should bear in mind that deregulation took place during different periods. As Danthine et al. (1999) point out, the deregulation in the 1980s occurred at national levels as well as through EU-wide measures, whereas from the late 1980s and going into the 1990s the EU started to harmonize bank regulation. ${ }^{5}$

The article proceeds as follows. After this introductory section, section 2 presents the methodology to measure both efficiency and productivity indices, while section 3 is devoted both to motivate and briefly explain bootstrapping techniques as applied to DEA. Section 4 provides data information, and section 5 presents and discusses the results. Finally, section 6 concludes.

\section{Measuring the efficiency and productivity of savings banks}

Nonparametric frontier techniques are used to measure both the efficiency and productivity of savings banks. We firstly present the details on the measurement of productivity and secondly examine how to measure efficiency. We chose to proceed in this way because the measurement of technical efficiency through nonparametric techniques is founded on the estimation of distance functions, analogously to productivity indices.

Productivity can be measured via either parametric and nonparametric methods. Within both approaches may be found those which ignore efficiency, as opposed to others which account for it. Grosskopf (1993) provides an excellent survey on this topic. We focus on nonparametric methods which account for inefficiency or, in other words, nonparametric frontier approaches. These have been widely used since the early eighties, after the influential works by Caves et al. (1982), which developed the Malmquist productivity index from the notion of "proportional scaling" introduced by Malmquist (1953). Caves et al. (1982) did not account for inefficiency, contrary to Färe et al. (1992), who combine ideas on measurement of efficiency from Farrell (1957) and on measurement of productivity from Caves et al. (1982) to develop a Malmquist index of productivity change.

To measure productivity growth we consider two periods, $t_{1}$ and $t_{2}$. In period $t_{1}$ firms produce output $\mathbf{y}^{t_{1}}$ by using input $\mathbf{x}^{t_{1}}$, whereas in period $t_{2}$ quantities are $\mathbf{y}^{t_{2}}$ and $\mathbf{x}^{t_{2}}$, respectively. The production set

\footnotetext{
${ }^{4}$ All important deregulation initiatives took place before 1991 . The only remaining change was the establishment of the Single European Market in 1993.

${ }^{5}$ For a recent overview of bank regulation and deregulation, see Freixas and Santomero (2002).
} 
$\mathcal{S}^{t}$ which models the transformation of inputs $\mathbf{x}^{t} \in \mathbb{R}_{+}^{N}$ into outputs $\mathbf{y}^{t} \in \mathbb{R}_{+}^{M}$ at time $t$ is:

$$
\mathcal{S}^{t}=\left\{\left(\mathbf{x}^{t}, \mathbf{y}^{t}\right): \mathbf{x}^{t} \text { can produce } \mathbf{y}^{t}\right\}
$$

which holds for $t_{1}$ and $t_{2}$.

Following Shephard (1970), the output distance function for a generic firm $i$ at $t_{1}$ is:

$$
D_{i}^{t_{1}}\left(\mathbf{x}_{i}^{t_{1}}, \mathbf{y}_{i}^{t_{1}}\right)=\inf \left\{\theta:\left(\mathbf{x}_{i}^{t_{1}}, \mathbf{y}_{i}^{t_{1}} / \theta\right) \in \mathcal{S}^{t_{1}}\right\}=\left(\sup \left\{\theta:\left(\mathbf{x}_{i}^{t_{1}}, \theta \mathbf{y}_{i}^{t_{1}}\right) \in \mathcal{S}^{t_{1}}\right\}\right)^{-1}
$$

where $\left(\mathbf{x}_{i}^{t_{1}}, \mathbf{y}_{i}^{t_{1}}\right)$ is the vector in $\mathbb{R}^{N+M}$ made up of firm $i$ 's inputs and outputs, and the quotient in the vector $\mathbf{y}_{i}^{t_{1}} / \theta$ is in relation to all its components. The same applies to $D_{i}^{t_{2}}\left(\mathbf{x}_{i}^{t_{2}}, \mathbf{y}_{i}^{t_{2}}\right)$. Equation (2) refers to the output distance function, and is simply the inverse of the Farrell (1957) output-oriented measure of technical efficiency. Note that $D_{i}^{t}\left(\mathbf{x}_{i}^{t}, \mathbf{y}_{i}^{t}\right) \leq 1$ if and only if $\left(\mathbf{x}_{i}^{t}, \mathbf{y}_{i}^{t}\right) \in \mathcal{S}^{t}$, which holds for both $t_{1}$ and $t_{2}$.

Computing the Malmquist productivity index requires two additional distance functions to be defined. One measures the maximum proportional change in outputs required to make $\left(\mathbf{x}_{i}^{t_{2}}, \mathbf{y}_{i}^{t_{2}}\right)$ feasible in relation to the technology at $t_{1}$, i.e.:

$$
D_{i}^{t_{1}}\left(\mathbf{x}_{i}^{t_{2}}, \mathbf{y}_{i}^{t_{2}}\right)=\inf \left\{\theta:\left(\mathbf{x}_{i}^{t_{2}}, \mathbf{y}_{i}^{t_{2}} / \theta\right) \in \mathcal{S}^{t_{1}}\right\}
$$

The second refers to the maximum proportional change in output required to make $\left(\mathbf{x}_{i}^{t_{1}}, \mathbf{y}_{i}^{t_{1}}\right)$ feasible in relation to the technology at $t_{2}$ :

$$
D_{i}^{t_{2}}\left(\mathbf{x}_{i}^{t_{1}}, \mathbf{y}_{i}^{t_{1}}\right)=\inf \left\{\theta:\left(\mathbf{x}_{i}^{t_{1}}, \mathbf{y}_{i}^{t_{1}} / \theta\right) \in \mathcal{S}^{t_{2}}\right\}
$$

A Malmquist productivity index between periods $t_{1}$ and $t_{2}, t_{1}<t_{2}$, can be defined as:

$$
M\left(\mathbf{x}_{i}^{t_{2}}, \mathbf{y}_{i}^{t_{2}}, \mathbf{x}_{i}^{t_{1}}, \mathbf{y}_{i}^{t_{1}}\right)=\left[\frac{D_{i}^{t_{1}}\left(\mathbf{x}_{i}^{t_{2}}, \mathbf{y}_{i}^{t_{2}}\right)}{D_{i}^{t_{1}}\left(\mathbf{x}_{i}^{t_{1}}, \mathbf{y}_{i}^{t_{1}}\right)} \frac{D_{i}^{t_{2}}\left(\mathbf{x}_{i}^{t_{2}}, \mathbf{y}_{i}^{t_{2}}\right)}{D_{i}^{t_{2}}\left(\mathbf{x}_{i}^{t_{1}}, \mathbf{y}^{t_{1}}\right)}\right]^{1 / 2}
$$

which is the geometric mean of the output-based Malmquist productivity indices for $t_{1}$ and $t_{2}$ defined by Caves et al. (1982). Alternatively, Färe et al. (1992) decompose (5) into the product of an index measuring changes in technical efficiency ("catching up") and another one capturing the shift in the production frontier ("technical change") as follows:

$$
M\left(\mathbf{x}_{i}^{t_{2}}, \mathbf{y}_{i}^{t_{2}}, \mathbf{x}_{i}^{t_{1}}, \mathbf{y}_{i}^{t_{1}}\right)=\underbrace{\frac{D_{i}^{t_{2}}\left(\mathbf{x}_{i}^{t_{2}}, \mathbf{y}_{i}^{t_{2}}\right)}{D_{i}^{t_{1}}\left(\mathbf{x}_{i}^{t_{1}}, \mathbf{y}_{i}^{t_{1}}\right)}}_{\text {Efficiency change }} \underbrace{\left[\frac{D_{i}^{t_{1}}\left(\mathbf{x}_{i}^{t_{2}}, \mathbf{y}_{i}^{t_{2}}\right)}{D_{i}^{t_{2}}\left(\mathbf{x}_{i}^{t_{2}}, \mathbf{y}_{i}^{t_{2}}\right)} \frac{D_{i}^{t_{1}}\left(\mathbf{x}_{i}^{t_{1}}, \mathbf{y}_{i}^{t_{1}}\right)}{D_{i}^{t_{2}}\left(\mathbf{x}_{i}^{t_{1}}, \mathbf{y}_{i}^{t_{1}}\right)}\right]^{1 / 2}}_{\text {Technical change }}
$$

The efficiency change component is an index of relative technical efficiency change, and shows how much closer (or farther away) a firm gets to the frontier made up by "best practice" firms. This component is greater than, equal to, or less than unity depending on whether the evaluated firm improves, stagnates, or declines. The technical change component measures how much the frontier shifts, and indicates 
whether the best practice relative to which the evaluated firm is compared is improving, stagnating, or deteriorating. In either case the index will take a value greater than, equal to, or less than unity - hence technical change is positive, zero, or negative.

Data consist of a known vector of inputs and outputs of $L$ firms at both periods $t=t_{1}, t_{2}$ :

$$
\mathcal{Z}=\left\{\left(\mathbf{x}_{i}^{t_{1}}, \mathbf{y}_{i}^{t_{1}}, \mathbf{x}_{i}^{t_{2}}, \mathbf{y}_{i}^{t_{2}}\right), i=1, \ldots, L\right\}
$$

where $\mathbf{x}_{i}^{t}=\left(x_{i 1}^{t}, \ldots, x_{i n}^{t}, \ldots, x_{i N}^{t}\right)^{\prime} \in \mathbb{R}_{+}^{N}$ is the observed value of each input for each firm $i$ at time $t$, and $\mathbf{y}_{i}^{t}=\left(y_{i 1}^{t}, \ldots, y_{i m}^{t}, \ldots, y_{i M}^{t}\right)^{\prime} \in \mathbb{R}_{+}^{M}$ is its output reciprocal.

Following Färe et al. (1992) the four components which make up equation (6) via linear programming techniques can be estimated. For this, we should consider the following linear program for firm $i, i=$ $1, \ldots, L$ :

$$
\left[\hat{D}_{i}^{t_{1}}\left(\mathbf{x}_{i}^{t_{1}}, \mathbf{y}_{i}^{t_{1}}\right)\right]^{-1}=\max \theta
$$

s.t.

$$
\begin{array}{cl}
\theta y_{i m}^{t_{1}} \leq \sum_{j=1}^{L} \lambda_{j}^{t_{1}} y_{m j}^{t_{1}}, & m=1 \ldots, M, \\
\sum_{j=1}^{L} \lambda_{j}^{t_{1}} x_{j n}^{t_{1}} \leq x_{i n}^{t_{1}}, & n=1, \ldots, N, \\
\lambda_{i}^{t_{1}} \geq 0, & i=1, \ldots, L .
\end{array}
$$

where $\lambda_{i}^{t_{1}}=\left(\lambda_{1}^{t_{1}}, \ldots, \lambda_{L}^{t_{1}}\right)^{\prime}$ is a vector of weights that forms a convex combination of observed firms relative to which the subject firm's efficiency is evaluated. Linear program (8) calculates the distances $\hat{D}_{i}^{t_{1}}\left(\mathbf{x}_{i}^{t_{1}}, \mathbf{y}_{i}^{t_{1}}\right)$. Computing $\hat{D}_{i}^{t_{2}}\left(\mathbf{x}_{i}^{t_{2}}, \mathbf{y}_{i}^{t_{2}}\right)$ is exactly like (8), where $t_{2}$ is substituted for $t_{1}$.

Two further linear programs are needed to estimate the mixed-period cases (3) and (4). The first of these is computed for each $i$ firm as:

$$
\begin{aligned}
& {\left[\hat{D}_{i}^{t_{1}}\left(\mathbf{x}_{i}^{t_{2}}, \mathbf{y}_{i}^{t_{2}}\right)\right]^{-1}=\max \theta} \\
& \text { s.t. } \\
& \qquad \begin{array}{cl}
\theta y_{i m}^{t_{2}} \leq \sum_{j=1}^{L} \lambda_{j}^{t_{1}} y_{m j}^{t_{1}}, & m=1 \ldots, M, \\
\sum_{j=1}^{L} \lambda_{j}^{t_{1}} x_{j n}^{t_{1}} \leq x_{i n}^{t_{2}}, & n=1, \ldots, N, \\
\quad \lambda_{i}^{t_{1}} \geq 0, & i=1, \ldots, L .
\end{array}
\end{aligned}
$$

As Färe et al. (1994) state, observations involved in (9) are from both period $t_{1}$ and $t_{2}$. The reference technology relative to which $\left(\mathbf{x}_{i}^{t_{2}}, \mathbf{y}_{i}^{t_{2}}\right)$ is evaluated is constructed from observations in $t_{1}$. To calculate the second mixed-period distance function, $D_{i}^{t_{2}}\left(\mathbf{x}_{i}^{t_{1}}, \mathbf{y}_{i}^{t_{1}}\right)$, the $t_{1}$ and $t_{2}$ superscripts in (9) must simply be reversed. Hereafter, and for the sake of simplicity, the distances involved in these four linear programs will be labelled $\hat{D}_{i}^{t_{1} \mid t_{1}}, \hat{D}_{i}^{t_{2} \mid t_{2}}, \hat{D}_{i}^{t_{2} \mid t_{1}}$ and $\hat{D}_{i}^{t_{1} \mid t_{2}}$, respectively.

Unlike other recent work (Wheelock and Wilson, 1999; Mukherjee et al., 2001), in which a further decomposition of the Malmquist productivity index is considered, we assume constant returns to scale (CRS), which is a common assumption, since Grifell-Tatjé and Lovell (1995b) have shown that in the context of non-constant returns to scale, the Malmquist index does not accurately measure productivity change. In the case of Spanish savings banks, it is not a substantial assumption, since some applied 
papers have found results of constant returns to scale or very close to them (Grifell-Tatjé and Lovell, 1995a; Grifell-Tatjé and Lovell, 1997; Raymond and García Greciano, 1994). In addition, assuming CRS allows a more direct comparison between our results and those by Grifell-Tatjé and Lovell (1996) and Pastor (1995). A further advantage of CRS is that results are coincidental regardless of whether we solve the linear programs under the input- or output-oriented approaches.

For efficiency measurement no additional formulation is needed. The distances involved in its computation have been already presented. Specifically, to measure the technical efficiency of a given Decision Making Unit, DMU, (savings bank) in period $t_{1}$ we would simply have to solve the inverse of (8). The same holds for measuring the efficiency of a given firm in period $t_{2}$, in which case we should consider the inverse of (8), replacing $t_{1}$ with $t_{2}$.

The interpretation is straightforward. Clearly, $\hat{D}_{i}^{t \mid t} \leq 1$, with $\hat{D}_{i}^{t \mid t}=1$ indicating that the $i^{\text {th }}$ firm lies on the boundary of the production set and is thus technically efficient. The other firms with scores below unity will be technically inefficient, producing less output at given input levels. For simplicity, when referring to efficiency scores and efficiency measurement, $\hat{D}_{i}^{t \mid t}$ will be labelled $\hat{\theta}_{i}$.

\section{Formulation of the bootstrap}

The presentation of the bootstrapping methodology closely follows that of Simar and Wilson (1998, 1999a). As will be emphasized throughout the presentation, the biggest problem when bootstrapping both productivity indices and efficiency scores is that of mimicking the DGP to allow the introduction of probability elements into the problem. Some previous applications of this methodology have failed in this attempt, hence providing inconsistent bootstrap estimation. ${ }^{6}$ Consequently, our basic attempt here is to apply the bootstrapping techniques introduced earlier by Efron (1979) and Efron and Tibshirani (1993), but with explicit care over the very particular DGP of both the Malmquist productivity indices and efficiency scores. In other words, we will not apply the so-called naive bootstrap, which consists of merely resampling from the original data, but rather we will consider the distributions underlying such distance functions.

An example is provided in figure 1. It shows the density functions (estimated nonparametrically using kernel smoothing) of technical efficiency scores for each sample period. The features revealed are manifold but, for our purposes, it must be noted that their shape is very peculiar. Specifically, in all cases a remarkable mode is observed at above unity. Furthermore, we must consider that, given that efficiency scores are bounded from above, there is no probability mass beyond 1. Silverman (1986) developed an interesting statistical procedure, the reflection method, to account for this. When using it to nonparametrically estimate density functions, results are satisfactory, as figure revealed in 2 . If all these features are not taken into account when mimicking the DGP, inconsistent bootstrap estimation is likely to occur. ${ }^{7}$ Also, it is interesting to note that efficiency scores approach over time, as density is much more concentrated in 1998 than it is in 1992, whether we use the reflection method or not. However, a

\footnotetext{
${ }^{6}$ For an illustration, see the debate in Lovell (2000), Ferrier and Hirschberg (1997, 1999), and Simar and Wilson (1999b,c).

${ }^{7}$ These ideas were initially suggested in conclusions put forward by Grosskopf (1996).
} 


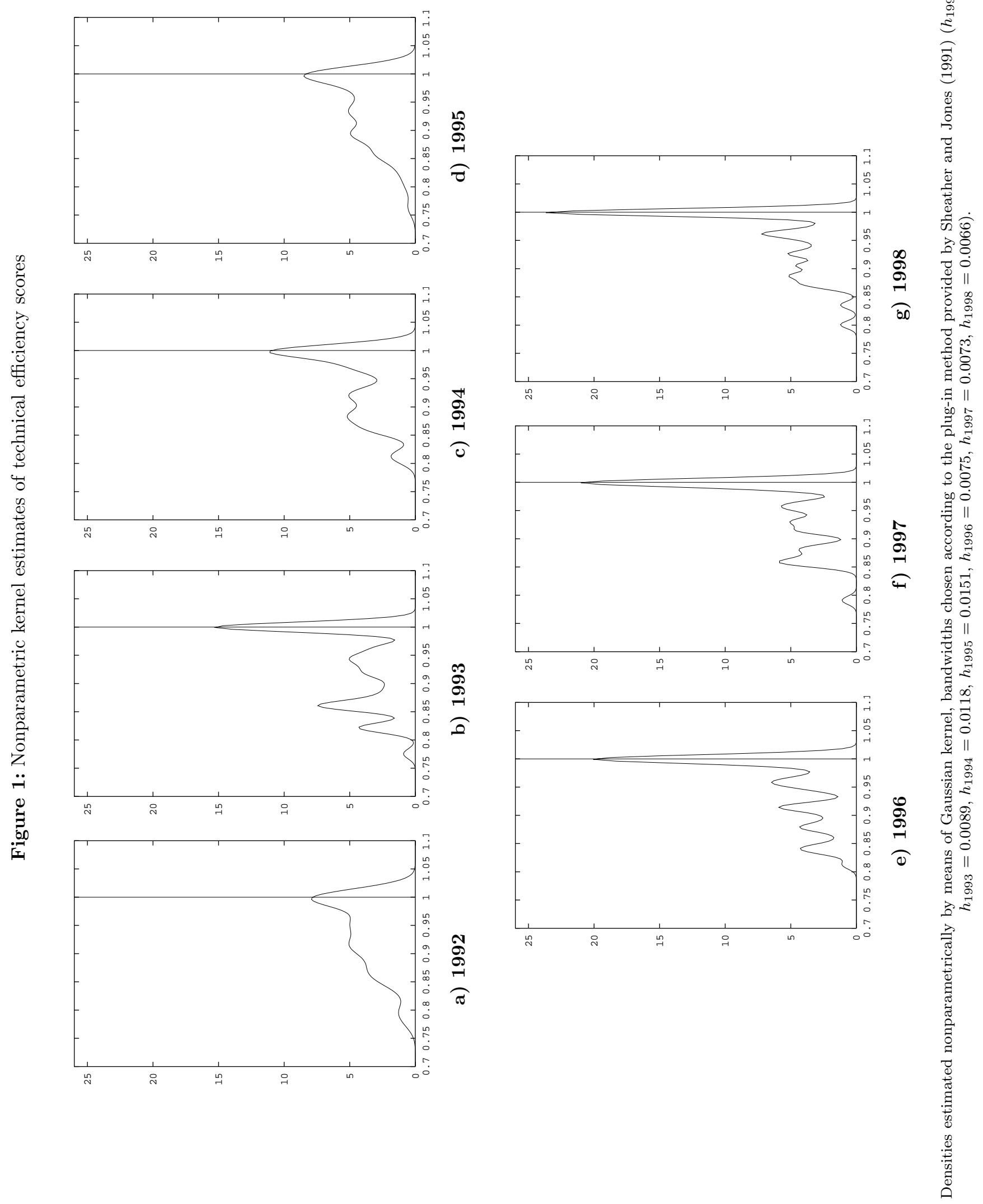




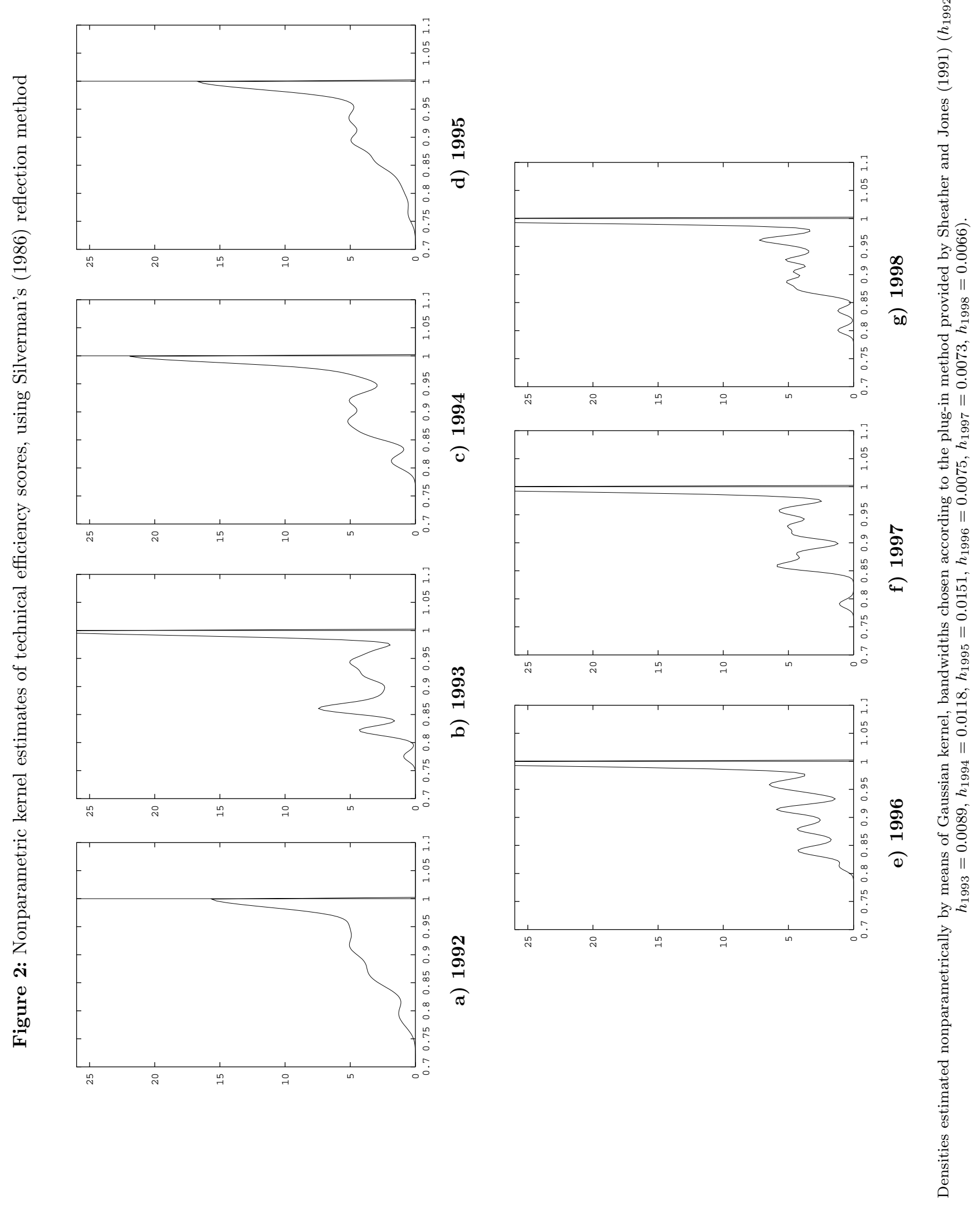


substantial amount of inefficiency still persists.

\subsection{Bootstrapping productivity indices}

Thus, our basic aim when bootstrapping the Malmquist productivity index is to replicate the DGP, so as to generate an appropriately large number $B$ of pseudo samples $\mathcal{Z}^{*}=\left\{\left(\mathbf{x}_{i}^{t_{1} *}, \mathbf{y}_{i}^{t_{1} *}, \mathbf{x}_{i}^{t_{2} *}, \mathbf{y}_{i}^{t_{2} *}, i=1, \ldots, L\right)\right\}$, and to apply the original estimators to these pseudo samples, i.e., we have to consider the bootstrap counterparts of programs (8) and (9), along with their reversals - i.e., we would have four linear programs. In the case of (8) we have for each $i$ firm, $i=1, \ldots, L$ :

$$
\begin{array}{ll}
{\left[\hat{D}_{i}^{t_{1} *}\left(\mathbf{x}_{i}^{t_{1} *}, \mathbf{y}_{i}^{t_{1} *}\right)\right]^{-1}=\max \theta} & \\
\text { s.t. } & m=1 \ldots, M, \\
\quad \theta y_{i m}^{t_{1} *} \leq \sum_{j=1}^{L} \lambda_{j}^{t_{1}} y_{m j}^{t_{1} *}, & n=1, \ldots, N, \\
\sum_{j=1}^{L} \lambda_{j}^{t_{1}} x_{j n}^{t_{1} *} \leq x_{i n}^{t_{1} *}, & i=1, \ldots, L . \\
\lambda_{i}^{t_{1}} \geq 0, &
\end{array}
$$

The bootstrap counterparts of the remaining programs are derived quite straightforwardly. For period $t_{2}$ we simply have to substitute $t_{1} *$ with $t_{2} *$.

In the case of program (9) we have:

$$
\begin{array}{ll}
{\left[\hat{D}_{i}^{t_{1} *}\left(\mathbf{x}_{i}^{t_{2} *}, \mathbf{y}_{i}^{t_{2} *}\right)\right]^{-1}=\max \theta} & \\
\text { s.t. } & m=1 \ldots, M, \\
\quad \theta y_{i m}^{t_{2} *} \leq \sum_{j=1}^{L} \lambda_{j}^{t_{1}} y_{m j}^{t_{1} *}, & n=1, \ldots, N, \\
\sum_{j=1}^{L} \lambda_{j}^{t_{1}} x_{j n}^{t_{1} *} \leq x_{i n}^{t_{2} *}, & i=1, \ldots, L, \\
\lambda_{i}^{t_{1}} \geq 0, &
\end{array}
$$

The fourth program, corresponding to the other mixed-period case, arises from reversing $t_{1} *$ and $t_{2} *$ in $(11)$.

Again, for simplicity, the solutions to these four programs will hereafter be labelled $\hat{D}_{i}^{t_{1} \mid t_{1} *}, \hat{D}_{i}^{t_{2} \mid t_{2} *}$, $\hat{D}_{i}^{t_{2} \mid t_{1} *}$ and $\hat{D}_{i}^{t_{1} \mid t_{2} *}$, respectively. Therefore, for each firm, and each two time periods $t_{1}, t_{2}$ we have $\left\{\hat{D}_{i}^{t_{1} \mid t_{1} *}(b), \hat{D}_{i}^{t_{2} \mid t_{2} *}(b), \hat{D}_{i}^{t_{2} \mid t_{1} *}(b), \hat{D}_{i}^{t_{1} \mid t_{2} *}(b)\right\}_{b=1}^{B}$, which can be easily substituted in (6) to construct bootstrap estimates of efficiency change, technical change, and Malmquist productivity indices.

The important point after computing these bootstrap estimates is to be able to construct confidence intervals at desired levels of significance. It is thus possible to assert whether productivity growth (or decline) measured by the Malmquist productivity index is significant, i.e., it is greater than (or less than) unity at the desired significance levels. ${ }^{8}$ The same holds for the sources of productivity, as assessing the significance of both efficiency change and technical change - if they occur - is now possible.

Therefore, our aim is to perform statistical inference using the bootstrap or, put another way, to make inferences about the Malmquist index for each firm by approximating the sampling distribution

\footnotetext{
${ }^{8}$ Obviously, the interpretation would be the opposite if the input-oriented case were considered. In such a case, productivity decline would be indicated by a Malmquist productivity index greater than unity.
} 
of its estimator, hereafter labelled $\hat{M}_{i}\left(t_{1}, t_{2}\right)$. Two complementary ways of doing this are through the development of an estimate of the bias $^{9}$ and through the development of confidence intervals. Our attention will be entirely confined to the latter. ${ }^{10}$

To estimate confidence intervals, we take into account that the bootstrap is based on the approximation of the unknown distribution $\hat{M}_{i}\left(t_{1}, t_{2}\right)-M_{i}\left(t_{1}, t_{2}\right)$ by the distribution $\hat{M}_{i}^{*}\left(t_{1}, t_{2}\right)-\hat{M}_{i}\left(t_{1}, t_{2}\right)$ conditioned on the original data-where $\hat{M}_{i}^{*}\left(t_{1}, t_{2}\right)$ is the bootstrap estimator of the Malmquist productivity index for firm $i$. If we knew the former distribution, then it would be trivial to find values $a_{\alpha}$ and $b_{\alpha}$ such that:

$$
\operatorname{Prob}\left(-b_{\alpha} \leq \hat{M}_{i}\left(t_{1}, t_{2}\right)-M_{i}\left(t_{1}, t_{2}\right) \leq-a_{\alpha}\right)=1-\alpha
$$

for the usual confidence levels $(\alpha=0.10, \alpha=0.05)$. Unfortunately, this distribution is unknown. Instead, the bootstrap values $\left\{\hat{M}_{i}^{*}\left(t_{1}, t_{2}\right)(b)\right\}_{b=1}^{B}$ to generate confidence intervals:

$$
\operatorname{Prob}\left(-b_{\alpha}^{*} \leq \hat{M}_{i}^{*}\left(t_{1}, t_{2}\right)-\hat{M}_{i}\left(t_{1}, t_{2}\right) \leq-a_{\alpha}^{*} \mid \mathcal{Z}\right)=1-\alpha
$$

Also, as it is true that when $B \rightarrow \infty$

$$
\left[\hat{M}_{i}\left(t_{1}, t_{2}\right)-M_{i}\left(t_{1}, t_{2}\right)\right] \stackrel{\text { approx }}{\sim}\left[\hat{M}_{i}^{*}\left(t_{1}, t_{2}\right)-\hat{M}_{i}\left(t_{1}, t_{2}\right)\right] \mid \mathcal{Z}
$$

we may conclude that

$$
\operatorname{Prob}\left(-b_{\alpha}^{*} \leq \hat{M}_{i}\left(t_{1}, t_{2}\right)-M_{i}\left(t_{1}, t_{2}\right) \leq-a_{\alpha}^{*} \mid \mathcal{Z}\right) \approx 1-\alpha
$$

It can easily be seen that the point is to find appropriate $a_{\alpha}^{*}$ and $b_{\alpha}^{*}$ values. This may be accomplished through mechanical sorting of the values $\left[\hat{M}_{i}^{*}\left(t_{1}, t_{2}\right)(b)-\hat{M}_{i}\left(t_{1}, t_{2}\right)\right], b=1, \ldots, B$ by algebraic value, then deleting $((\alpha / 2) \times 100)$-percent of the elements at either end, and finally setting $-b_{\alpha}^{*}$ and $-a_{\alpha}^{*}$ equal to the extreme parts of the resulting sorted array, meeting the condition $a_{\alpha}^{*} \leq b_{\alpha}^{*}$. This method is known as the percentile method.

Once both values have been obtained, by rearranging terms in (15) we obtain:

$$
\hat{M}_{i}\left(t_{1}, t_{2}\right)+a_{\alpha}^{*} \leq M_{i}\left(t_{1}, t_{2}\right) \leq \hat{M}_{i}\left(t_{1}, t_{2}\right)+b_{\alpha}^{*}
$$

which is a $(1-\alpha) \%$ confidence interval indicating that productivity growth, or productivity decline, has occurred at a significant level if the interval does not include unity. On the contrary, if the interval included the unity we would conclude that there has been no productivity change (either growth or decline) for firm $i$, even if the original Malmquist productivity index were different from one-i.e., productivity growth, or decline, is not significantly different from unity.

The procedure outlined above would yield inconsistent bootstrap estimates unless we replicated the

\footnotetext{
${ }^{9}$ The rationale for this is provided by Mooney and Duval (1993).

${ }^{10}$ Simar and Wilson (1999a) provide such an estimate of the bias for the Malmquist productivity index .
} 
DGP consistently. This task is of great relevance in our specific setting, in which data generated by distance functions are bounded. Specifically, employing the empirical distribution would yield inconsistent estimates, as it places a positive probability mass at the boundary of the estimated production set, which does not vanish as $L \rightarrow \infty$.

In order to overcome this problem, and following Simar and Wilson (1999a), we may attempt to estimate the density of the original distance function estimates, and then draw from this density to construct pseudo samples $\mathcal{Z}^{*}$. As we closely follow Simar and Wilson (1999a), all details have been omitted for brevity.

\subsection{Bootstrapping efficiency scores}

Measuring efficiency does not require panel data. Our attention is confined to (10) - or its $t_{2}$ version. This implies that the DGP is now different. In particular, and keeping in mind the smoothed version of the bootstrap that we are considering, our first interest is now how to make inference, once we have a large bootstrap sample $\left\{\hat{\theta}_{i b}^{*}\right\}_{b=1}^{B}$.

As the bootstrap is based on the idea that if we have a reasonable (consistent) estimator of the DGP, the bootstrap distribution will mimic the original sampling distribution of the estimators of interest, then we can estimate the bias of each estimation $\hat{\theta}_{i}$ using the bootstrap sample as

$$
\widehat{\operatorname{bias}}_{i}=\bar{\theta}_{i}^{*}-\hat{\theta}_{i}
$$

where $\bar{\theta}_{i}^{*}=\frac{1}{B} \sum_{b=1}^{B} \hat{\theta}_{i b}^{*}$. We can then obtain a bias corrected estimator for $\theta_{i}$ as:

$$
\tilde{\theta}_{i}=2 \hat{\theta}_{i}-\bar{\theta}_{i}^{*}
$$

Moreover, the empirical distribution of $\left\{\hat{\theta}_{i b}^{*}\right\}_{b=1}^{B}$ provides, after correction for bias, confidence intervals for $\hat{\theta}_{i}$ :

$$
\left(\hat{\theta}_{i, \text { low }}, \hat{\theta}_{i, \mathrm{up}}\right)=\left(\tilde{\theta}_{i}^{*(\alpha)}, \tilde{\theta}_{i}^{*(1-\alpha)}\right)
$$

where $\tilde{\theta}_{i}^{*(\alpha)}$ is the $100 \alpha^{\text {th }}$ percentile of the empirical distribution of the corrected for bias distribution denoted by $\left\{\tilde{\theta}_{i b}^{*}\right\}_{b=1}^{B}$.

It is worth noting that if this distribution is skewed, we can use also median-bias corrected confidence intervals. ${ }^{11}$ As in the Malmquist productivity index case, all details regarding the DGP follow the contribution by Simar and Wilson (1998), and consequently have been omitted for reasons of space.

\footnotetext{
${ }^{11}$ See Efron and Tibshirani (1993) and Simar and Wilson (1998) for details.
} 


\section{Data}

\subsection{The sample}

Data are provided by the Spanish savings banks association (CECA, Confederación Española de Cajas de Ahorro). The firms which were not in continuous existence over the sample period 1992-1998 were dropped, and savings banks were backward merged in order to have the same number of firms in every year. Although this might a priori involve both losing information and creating artificial companies, neither of these two cases occurs. First, virtually all firms were in continuous existence over the sample period. Second, the only firms which were not were those involved in M\&A's. However, the consolidation process was nearly over in 1992. Since then, there have been only three consolidations, which affected only small firms. Hence, in order to include all firms, and to obtain a complete panel, we judged it a reasonable strategy to backward merge these firms. Two of these consolidations took place in 1992, and the third occurred in $1994 .^{12}$

\subsection{Inputs and outputs}

Our way of measuring the flow of services provided by savings banks follows the intermediation approach, which considers firms as primarily intermediating funds between savers and investors, in contrast to the production approach, which treats financial institutions as primarily producing services for account holders. A different issue, often confused with the former, refers to the definition of outputs (TortosaAusina, 2002a). The asset, user cost, and value-added methods are three different ways of assigning input or output nature to the different balance sheet categories. They differ, among other aspects, in the role attached to deposits. Our approach is in line with the asset approach, as it primarily treats earning assets as bank output. However, it is generally accepted that most banks raise a substantial portion of their funds through produced deposits and provide liquidity, payments, and safekeeping services to depositors to obtain these funds. In order to capture these activities, we have included core deposits as an additional output category-hence, our approach will be closer to the value-added approach. In addition, in line with the contributions by Rogers (1998) and Rogers and Sinkey Jr (1999), and with the European Central Bank (2000), we consider an additional output to control for the nontraditional activities performed by banks. All variables are described in table 1, which also reports descriptive statistics.

Therefore, our choice considers three outputs and three inputs. Our first output category is loans $\left(y_{1}\right)$, defined as all forms of loans performed by savings banks. This is virtually the only asset category unanimously treated as bank output by the different output definitions. It would be desirable to disaggregate it, but the lack of precise statistical information rules out this possibility. The second output is savings, time, and transactions deposits $\left(y_{2}\right)$. Ideally, this category should include only transactions deposits, given that our purpose is to proxy the liquidity, payments, and safekeeping services provided. Unfortunately, public information only disentangles savings deposits, other deposits, and interbank deposits. We label this category as "core" deposits, following Kumbhakar et al. (2001). Finally, we followed

\footnotetext{
${ }^{12}$ This strategy, however, is only followed so as to ease presentation and interpretation of results.
} 


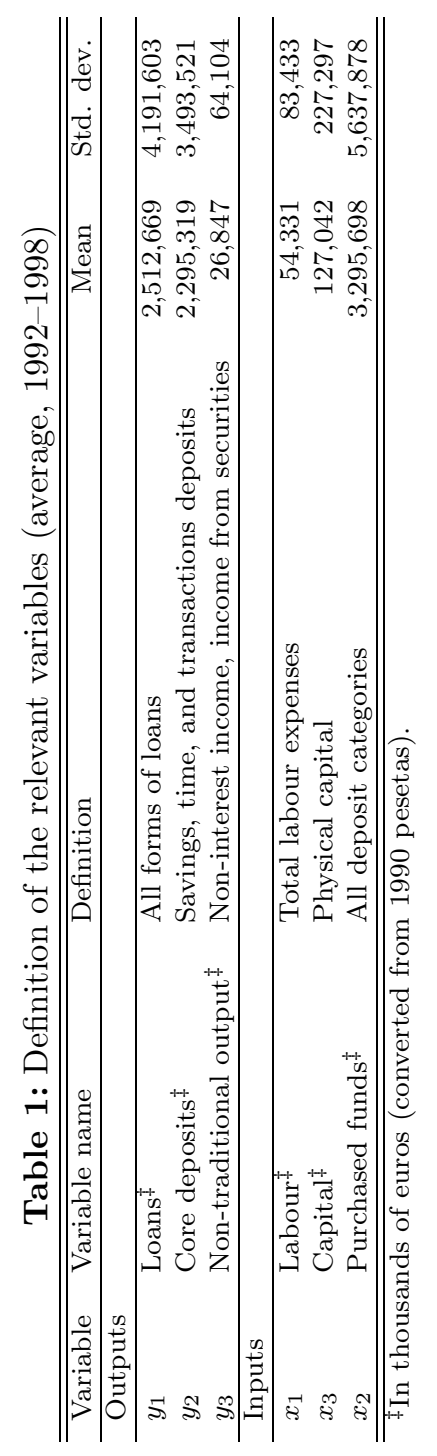


some recent contributions which claim the "decline" of traditional banking (Gorton and Rosen, 1995), and others which, following these ideas, suggest that a proxy should be included to account for nontraditional activities (Rogers, 1998; Rogers and Sinkey Jr, 1999). Hence, our third output category ( $\left.y_{3}\right)$ includes mainly noninterest income, following Rogers (1998). The rationale for this also comes from the increase in mutual funds to the detriment of deposits which occurred during the sample years. Additionally, we included the income from securities in this category, as many savings banks took part in the privatization process of certain public companies which occurred in the latter years of the sample, given that less regulated-conditioned output mixes could be chosen.

In the case of the inputs, the consensus in the literature is far broader. We include two traditional inputs, labour $\left(x_{1}\right)$ and capital $\left(x_{2}\right)$, measured by total labour expenses and physical capital, respectively. We also include purchased funds $\left(x_{3}\right)$, including all deposits categories, since this category generates roughly two thirds of total bank costs (Tortosa-Ausina, 2002b).

\section{Assessing efficiency and productivity differences: cross-section and time disparities}

\subsection{Productivity growth}

Changes in efficiency, technology, and productivity are reported in tables 2, 3, and 4, respectively, for both pairs of consecutive years and the sub-periods 1992-1995, 1995-1998 and the whole sample period 1992-1998. The last row in each table reports the mean for each selected pair of years. ${ }^{13}$ Although the exposition, and computation, was performed in terms of input-oriented indices, the reciprocal (outputoriented) was considered to disclose results for ease of interpretation. Accordingly, values above unity indicate improvement in productivity, efficiency, or technical change between periods $t_{1}$ and $t_{2}$, and vice versa.

Table 4 suggests that by 1998 savings banks were providing, on average, $119 \%$ as much output per unit of input as in 1992. In no year does the mean of the savings banks Malmquist productivity index equal, or is below unity. Productivity growth is especially high during the 1995/98 period, in which the rate of productivity growth was 11.56\%, due to increases in periods 1995/96, 1996/97 and 1997/98 of 1.86\%, $3.72 \%$ and $4.81 \%$, respectively. In the initial post-deregulation years, productivity growth also existed, although the gains occurred at more modest rates - in 1994/95 the increase was of $0.26 \%$.

Suitable explanations for these trends come from the decomposition of the Malmquist productivity index. The last row in table 3 reveals that productivity growth is attributable to a great extent to an improvement in "best practice" or, in other words, in production possibilities. An accurate examination of those figures in the last row of both tables 3 and 4 discloses that they are quite similar in periods 1996/97, 1997/98 and 1992/95. On the other hand, the last row in table 2 suggests that catching up with "best practice" improved productivity, although at far more modest rates. Specifically, efficiency improvements

\footnotetext{
${ }^{13}$ In the case of the mean, significance was determined by appealing to the central limit theorem, which requires independence among the efficiency estimates Wheelock and Wilson (1999). Given the inherent dependency of DEA efficiency scores, the indicated significance is at best only.
} 
Table 2: Changes in efficiency, consecutive years and sub-periods

\begin{tabular}{|c|c|c|c|c|c|c|c|c|c|}
\hline Firm & $1992 / 93$ & $1993 / 94$ & $1994 / 95$ & $1995 / 96$ & $1996 / 97$ & $1997 / 98$ & $1992 / 95$ & $1995 / 98$ & $1992 / 98$ \\
\hline 1 & $0.8626^{* *}$ & $1.0663^{* *}$ & $0.9578^{* *}$ & $1.0358^{* *}$ & 1.0057 & $1.0683^{* *}$ & $0.8809^{* *}$ & $1.1128^{* *}$ & 0.9803 \\
\hline 2 & 1.0046 & $0.9651^{* *}$ & 0.9960 & $1.0336^{* *}$ & $1.0243^{* *}$ & 1.0102 & $0.9658^{* *}$ & $1.0695^{* *}$ & 1.0329 \\
\hline 3 & 1.0000 & 1.0000 & 1.0000 & 1.0000 & 1.0000 & 1.0000 & 1.0000 & 1.0000 & 1.0000 \\
\hline 4 & 0.9993 & $0.9527^{* *}$ & $1.0424^{* *}$ & 0.9941 & $1.0289^{* *}$ & $1.0663^{* *}$ & 0.9924 & $1.0907^{* *}$ & $1.0824^{* *}$ \\
\hline 5 & $1.1283^{* *}$ & 1.0264 & 0.9763 & $1.0491^{* *}$ & 0.9991 & $0.9121^{* *}$ & $1.1305^{* *}$ & $0.9561^{* *}$ & $1.0809^{* *}$ \\
\hline 6 & 1.0000 & 1.0000 & 1.0000 & 1.0000 & 1.0000 & 1.0000 & 1.0000 & 1.0000 & 1.0000 \\
\hline 7 & $1.0492^{* *}$ & 1.0000 & 1.0000 & 1.0000 & 1.0000 & 1.0000 & $1.0492^{* *}$ & 1.0000 & $1.0492^{* *}$ \\
\hline 8 & $0.9398^{* *}$ & $1.0464^{* *}$ & 0.9910 & $1.0272^{* *}$ & 0.9958 & $1.0708^{* *}$ & 0.9745 & $1.0954^{* *}$ & $1.0674^{* *}$ \\
\hline 9 & 1.0061 & $1.0356^{*}$ & 0.9806 & 1.0062 & 1.0000 & 1.0135 & 1.0218 & 1.0198 & $1.0420^{*}$ \\
\hline 10 & 1.0130 & $0.9399^{* *}$ & $1.0509^{* *}$ & $1.0752^{* *}$ & $0.9547^{* *}$ & $0.9835^{*}$ & 1.0006 & 1.0095 & 1.0101 \\
\hline 11 & 1.0000 & $0.9213^{* *}$ & 0.9975 & $1.0397^{* *}$ & $1.0305^{* *}$ & $0.9652^{* *}$ & $0.9191^{* *}$ & $1.0341^{*}$ & $0.9504^{* *}$ \\
\hline 12 & 1.0000 & 1.0000 & 1.0000 & 1.0000 & $0.9289^{* *}$ & $0.9568^{* *}$ & 1.0000 & $0.8889^{* *}$ & $0.8889^{* *}$ \\
\hline 13 & $1.0852^{* *}$ & $0.8872^{* *}$ & $1.0441^{* *}$ & $0.9469^{* *}$ & $0.9772^{* *}$ & $0.9750^{* *}$ & 1.0052 & $0.9022^{* *}$ & $0.9068^{* *}$ \\
\hline 14 & $1.0405^{* *}$ & $1.0536^{* *}$ & $0.9267^{* *}$ & $1.0789^{* *}$ & $1.0394^{* *}$ & $0.9609^{* *}$ & 1.0160 & $1.0775^{* *}$ & $1.0947^{* *}$ \\
\hline 15 & $1.0438^{* *}$ & 1.0074 & $1.0549^{* *}$ & 1.0000 & 1.0000 & 1.0000 & $1.1092^{* *}$ & 1.0000 & $1.1092^{* *}$ \\
\hline 16 & $1.0348^{* *}$ & $0.9777^{* *}$ & 1.0195 & $1.0206^{*}$ & $1.0263^{* *}$ & $1.0194^{*}$ & 1.0314 & $1.0678^{* *}$ & $1.1013^{* *}$ \\
\hline 17 & 0.9825 & $0.9701^{* *}$ & 0.9956 & $0.9835^{*}$ & 1.0184 & 1.0083 & $0.9490^{* *}$ & 1.0099 & $0.9583^{* *}$ \\
\hline 18 & 0.9988 & $1.2497^{* *}$ & $0.9211^{* *}$ & $0.9471^{* *}$ & $1.1316^{* *}$ & 1.0077 & $1.1497^{* *}$ & $1.0799^{* *}$ & $1.2416^{* *}$ \\
\hline 19 & $1.0471^{* *}$ & 1.0000 & 1.0000 & 1.0000 & 1.0000 & 1.0000 & $1.0472^{* *}$ & 1.0000 & $1.0472^{* *}$ \\
\hline 20 & 1.0000 & 1.0000 & 1.0000 & $0.9995^{* *}$ & $1.0005^{* *}$ & 1.0000 & 1.0000 & 1.0000 & 1.0000 \\
\hline 21 & 1.0050 & $1.0600^{* *}$ & $0.9302^{* *}$ & $1.0238^{*}$ & 1.0040 & $1.0423^{* *}$ & 0.9910 & $1.0713^{* *}$ & $1.0618^{* *}$ \\
\hline 22 & 1.0000 & 1.0000 & 1.0000 & 1.0000 & 0.9889 & $0.9171^{* *}$ & 1.0000 & $0.9069^{* *}$ & $0.9069^{* *}$ \\
\hline 23 & $0.9414^{* *}$ & $1.0794^{* *}$ & $0.8624^{* *}$ & $1.1465^{* *}$ & $1.0761^{* *}$ & 0.9994 & $0.8764^{* *}$ & $1.2330^{* *}$ & $1.0805^{* *}$ \\
\hline 24 & $0.9476^{* *}$ & 1.0229 & 1.0081 & $1.0608^{* *}$ & $0.9690^{* *}$ & $1.0532^{* *}$ & 0.9771 & $1.0826^{* *}$ & $1.0579^{* *}$ \\
\hline 25 & $0.9655^{* *}$ & $0.9681^{* *}$ & $1.1569^{* *}$ & 0.9752 & $0.9567^{* *}$ & $1.0358^{* *}$ & $1.0813^{* *}$ & $0.9664^{*}$ & $1.0450^{* *}$ \\
\hline 26 & $0.9576^{* *}$ & 1.0080 & $1.0808^{* *}$ & $1.0443^{* *}$ & 1.0000 & 0.9952 & $1.0432^{* *}$ & $1.0393^{* *}$ & $1.0843^{* *}$ \\
\hline 27 & 1.0000 & 1.0000 & 0.9728 & $0.9837^{*}$ & 0.9957 & $1.0496^{* *}$ & 0.9728 & 1.0280 & 1.0000 \\
\hline 28 & 1.0025 & 1.0209 & $0.9302^{* *}$ & $1.0181^{*}$ & $1.0515^{* *}$ & $1.0373^{* *}$ & $0.9520^{* *}$ & $1.1106^{* *}$ & $1.0573^{* *}$ \\
\hline 29 & 1.0000 & 0.9955 & $0.9727^{*}$ & $1.0326^{* *}$ & 1.0000 & 0.9982 & 0.9684 & $1.0308^{*}$ & 0.9982 \\
\hline 30 & $1.0361^{* *}$ & $1.0410^{* *}$ & $1.0679^{* *}$ & 0.9933 & $0.9317^{* *}$ & $1.0221^{*}$ & $1.1517^{* *}$ & $0.9459^{* *}$ & $1.0894^{* *}$ \\
\hline 31 & 1.0003 & 1.0031 & $1.0602^{* *}$ & $1.0685^{* *}$ & 1.0000 & 1.0000 & $1.0639^{* *}$ & $1.0685^{* *}$ & $1.1367^{* *}$ \\
\hline 32 & 0.9761 & $1.0578^{* *}$ & 0.9969 & 1.0030 & 1.0000 & $0.9659^{* *}$ & $1.0293^{*}$ & $0.9688^{* *}$ & 0.9972 \\
\hline 33 & 1.0000 & 1.0000 & 1.0000 & 1.0000 & 1.0000 & 1.0000 & 1.0000 & 1.0000 & 1.0000 \\
\hline 34 & 0.9976 & $0.9746^{*}$ & 0.9975 & $1.0239^{*}$ & 1.0073 & 1.0000 & 0.9697 & 1.0312 & 1.0000 \\
\hline 35 & 0.9949 & 1.0192 & $0.9239^{* *}$ & $0.9671^{* *}$ & $0.9510^{* *}$ & 1.0122 & $0.9369^{* *}$ & $0.9310^{* *}$ & $0.8723^{* *}$ \\
\hline 36 & 0.9751 & $1.0531^{* *}$ & $1.0341^{* *}$ & $1.0634^{* *}$ & $0.9653^{* *}$ & 0.9930 & $1.0619^{* *}$ & 1.0194 & $1.0825^{* *}$ \\
\hline 37 & $0.9545^{* *}$ & $1.0377^{* *}$ & $1.0410^{* *}$ & $1.0211^{*}$ & $1.0583^{* *}$ & $0.9376^{* *}$ & 1.0310 & 1.0132 & $1.0446^{*}$ \\
\hline 38 & $0.9630^{* *}$ & 0.9979 & 1.0135 & 1.0156 & $1.0420^{* *}$ & $0.9505^{* *}$ & $0.9740^{*}$ & 1.0068 & 0.9806 \\
\hline 39 & 1.0000 & 1.0000 & 1.0000 & 1.0000 & 1.0000 & 0.9982 & 1.0000 & 1.0000 & 1.0000 \\
\hline 40 & $0.8728^{* *}$ & $1.0461^{* *}$ & $0.9310^{* *}$ & 1.0172 & $1.0676^{* *}$ & $1.0676^{* *}$ & $0.8500^{* *}$ & $1.1593^{* *}$ & 0.9854 \\
\hline 41 & $0.9084^{* *}$ & $1.0646^{* *}$ & 1.0161 & $0.9469^{* *}$ & $0.9751^{* *}$ & 1.0130 & 0.9826 & $0.9354^{* *}$ & $0.9191^{* *}$ \\
\hline 42 & 1.0300 & 0.9792 & 1.0073 & 1.0138 & $0.9504^{* *}$ & $0.9730^{* *}$ & 1.0160 & $0.9375^{* *}$ & $0.9525^{* *}$ \\
\hline 43 & 1.0000 & 0.9805 & 0.9921 & 0.9919 & $0.9652^{* *}$ & $1.0740^{* *}$ & 0.9727 & $1.0281^{*}$ & 1.0000 \\
\hline 44 & $1.0182^{*}$ & $0.9433^{* *}$ & $0.9536^{* *}$ & $1.0337^{* *}$ & 0.9901 & $1.0271^{* *}$ & $0.9158^{* *}$ & $1.0512^{* *}$ & $0.9628^{* *}$ \\
\hline 45 & 0.9951 & $1.0678^{* *}$ & $1.1018^{* *}$ & 0.9832 & 1.0081 & 1.0089 & $1.1708^{* *}$ & 1.0000 & $1.1708^{* *}$ \\
\hline 46 & $1.0244^{*}$ & $1.0379^{* *}$ & 1.0075 & $1.0493^{* *}$ & 0.9876 & 0.9977 & $1.0712^{* *}$ & $1.0339^{*}$ & $1.1076^{* *}$ \\
\hline 47 & $0.9782^{*}$ & 0.9961 & 0.9753 & $0.9322^{* *}$ & 1.0193 & $1.0351^{* *}$ & $0.9503^{* *}$ & 0.9835 & $0.9346^{* *}$ \\
\hline 48 & 1.0000 & 1.0000 & $0.8955^{* *}$ & 0.9827 & 1.0025 & 1.0115 & $0.8955^{* *}$ & 0.9964 & $0.8923^{* *}$ \\
\hline 49 & $0.9285^{* *}$ & $1.0414^{* *}$ & $1.0458^{* *}$ & 1.0000 & 1.0000 & 1.0000 & 1.0113 & 1.0000 & 1.0113 \\
\hline 50 & $1.0675^{* *}$ & $1.0224^{*}$ & $0.9409^{* *}$ & $1.0403^{* *}$ & $1.0338^{* *}$ & 1.0000 & 1.0269 & $1.0755^{* *}$ & $1.1044^{* *}$ \\
\hline Mean & 0.9944 & 1.0111 & 0.9960 & $1.0127^{* *}$ & 1.0025 & 1.0040 & 1.0015 & $1.0194^{* *}$ & $1.0209^{* *}$ \\
\hline
\end{tabular}

$\left({ }^{*}\right),\left({ }^{* *}\right)$ : significant differences from unity at $10 \%$ and $5 \%$, respectively. In the case of the mean, significance was determined by appealing to the central limit theorem. 
Table 3: Changes in technology, consecutive years and sub-periods

\begin{tabular}{|c|c|c|c|c|c|c|c|c|c|}
\hline Firm & $1992 / 93$ & $1993 / 94$ & $1994 / 95$ & $1995 / 96$ & $1996 / 97$ & $\begin{array}{l}1997 / 98 \\
\end{array}$ & $1992 / 95$ & $1995 / 98$ & $1992 / 98$ \\
\hline 1 & $1.0368^{* *}$ & 1.0172 & $1.0390^{* *}$ & $0.9699^{* *}$ & 1.0092 & $1.0379^{* *}$ & $1.1094^{* *}$ & $1.0671^{* *}$ & $1.1162^{* *}$ \\
\hline 2 & $1.0446^{* *}$ & 1.0069 & 1.0081 & $0.9810^{* *}$ & 1.0085 & $1.0161^{* *}$ & $1.0630^{* *}$ & 1.0097 & $1.0410^{* *}$ \\
\hline 3 & $1.0951^{* *}$ & 1.0510 & 1.0187 & $1.1203^{* *}$ & $1.1320^{* *}$ & $1.0585^{* *}$ & $1.2005^{* *}$ & $1.3209^{* *}$ & $1.5479^{* *}$ \\
\hline 4 & 0.9888 & 1.0158 & 0.9880 & 1.0119 & $1.0336^{* *}$ & $1.0777^{* *}$ & 1.0164 & $1.1475^{* *}$ & $1.3778^{* *}$ \\
\hline 5 & 0.9987 & 0.9814 & $0.9802^{*}$ & 1.0251 & $1.0890^{* *}$ & $1.0921^{* *}$ & $0.9671^{* *}$ & $1.2247^{* *}$ & $1.2960^{* *}$ \\
\hline 6 & 1.0316 & 0.9842 & $0.9509^{*}$ & $0.9655^{*}$ & 1.0094 & 1.0087 & 0.9653 & 1.0024 & $1.0640^{* *}$ \\
\hline 7 & $1.0356^{* *}$ & $1.1051^{* *}$ & $1.0452^{*}$ & 1.0027 & $1.0583^{* *}$ & $1.1459^{* *}$ & $1.1606^{* *}$ & $1.2508^{* *}$ & $1.4312^{* *}$ \\
\hline 8 & $1.0399^{* *}$ & 1.0042 & 1.0024 & 1.0135 & $1.0191^{*}$ & $1.0280^{* *}$ & 1.0072 & $1.0631^{* *}$ & $1.0903^{* *}$ \\
\hline 9 & $1.0432^{* *}$ & 1.0137 & 0.9805 & 1.0129 & 1.0180 & $1.0954^{* *}$ & $1.0750^{* *}$ & $1.2028^{* *}$ & $1.2225^{* *}$ \\
\hline 10 & $1.0433^{* *}$ & $1.0143^{*}$ & $1.0151^{* *}$ & $0.9693^{* *}$ & 1.0026 & 1.0080 & $1.0746^{* *}$ & 0.9906 & $1.0347^{* *}$ \\
\hline 11 & $1.0363^{* *}$ & 1.0124 & 1.0152 & $0.9607^{* *}$ & 0.9963 & $1.0321^{* *}$ & $1.0642^{* *}$ & 1.0114 & 1.0128 \\
\hline 12 & $1.0481^{* *}$ & $0.9276^{* *}$ & $1.0236^{* *}$ & $0.9817^{* *}$ & $1.0572^{* *}$ & $1.0444^{* *}$ & 0.9946 & $1.0750^{* *}$ & $1.1247^{* *}$ \\
\hline 13 & $1.0479^{* *}$ & 1.0205 & $0.9716^{* *}$ & 0.9982 & $1.0136^{* *}$ & $1.0325^{* *}$ & $1.0364^{* *}$ & $1.0876^{* *}$ & $1.0874^{* *}$ \\
\hline 14 & $1.0570^{* *}$ & $1.0487^{* *}$ & $1.0446^{* *}$ & $0.9675^{* *}$ & $1.0450^{* *}$ & $1.0606^{* *}$ & $1.0749^{* *}$ & $1.0532^{* *}$ & $1.1465^{* *}$ \\
\hline 15 & 1.0088 & $1.0249^{* *}$ & $1.0245^{* *}$ & 0.9848 & $1.0805^{* *}$ & $1.0960^{* *}$ & $1.0431^{* *}$ & $1.1475^{* *}$ & $1.1853^{* *}$ \\
\hline 16 & $1.0460^{* *}$ & $0.9846^{*}$ & 1.0000 & $0.9758^{* *}$ & $1.0184^{* *}$ & $1.0275^{* *}$ & $1.0301^{* *}$ & 1.0073 & 0.9939 \\
\hline 17 & $1.0354^{* *}$ & $1.0141^{*}$ & 1.0050 & 0.9931 & 1.0005 & 1.0109 & $1.0592^{* *}$ & 0.9971 & $1.0682^{* *}$ \\
\hline 18 & 1.0075 & 1.0029 & 1.0137 & $1.0465^{* *}$ & $1.0391^{* *}$ & $1.0879^{* *}$ & 1.0129 & $1.2428^{* *}$ & $1.3469^{* *}$ \\
\hline 19 & $1.0342^{* *}$ & $0.9557^{* *}$ & 0.9780 & $1.0205^{* *}$ & 1.0136 & $1.0293^{* *}$ & $0.9520^{* *}$ & $1.0823^{* *}$ & $1.0699^{* *}$ \\
\hline 20 & $1.0478^{* *}$ & 1.0032 & $1.0660^{* *}$ & $0.9673^{*}$ & 0.9903 & $0.9465^{* *}$ & $1.1385^{* *}$ & $0.9511^{* *}$ & 1.0397 \\
\hline 21 & $1.0220^{* *}$ & $0.9735^{* *}$ & 0.9982 & 1.0118 & 1.0170 & $1.0394^{* *}$ & 0.9999 & $1.0744^{* *}$ & $1.0990^{* *}$ \\
\hline 22 & $1.0590^{* *}$ & 0.9811 & 0.9710 & 1.0108 & 1.0454 & $1.0908^{* *}$ & 1.0427 & $1.1703^{* *}$ & $1.3416^{* *}$ \\
\hline 23 & $1.1334^{* *}$ & $0.9047^{* *}$ & $1.0347^{* *}$ & $0.9703^{* *}$ & 1.0143 & $1.0513^{* *}$ & $1.0423^{*}$ & $1.0406^{* *}$ & $1.0748^{* *}$ \\
\hline 24 & $1.0263^{*}$ & $1.0171^{*}$ & $1.0235^{* *}$ & 1.0031 & $1.0702^{* *}$ & $1.0749^{* *}$ & $1.1031^{* *}$ & $1.0946^{* *}$ & $1.3559^{* *}$ \\
\hline 25 & 0.9984 & 1.0002 & $1.0376^{* *}$ & 1.0221 & $1.0431^{* *}$ & $1.0675^{* *}$ & $1.0838^{* *}$ & $1.1775^{* *}$ & $1.3381^{* *}$ \\
\hline 26 & $1.0248^{* *}$ & 1.0056 & 1.0009 & 0.9936 & $1.0418^{* *}$ & 1.0260 & 1.0040 & $1.0774^{* *}$ & $1.1229^{* *}$ \\
\hline 27 & 0.9932 & $0.9748^{*}$ & $0.9470^{* *}$ & 1.0177 & $1.0232^{* *}$ & $1.0212^{* *}$ & $0.9122^{* *}$ & $1.0681^{* *}$ & 1.0500 \\
\hline 28 & $1.0578^{* *}$ & $1.0540^{* *}$ & $1.0789^{* *}$ & 0.9782 & 1.0114 & $1.0244^{* *}$ & $1.1899^{* *}$ & 0.9968 & $1.1863^{* *}$ \\
\hline 29 & $1.0342^{* *}$ & 1.0000 & 0.9946 & $0.9815^{* *}$ & $1.0163^{*}$ & 1.0155 & 1.0261 & $1.0302^{* *}$ & $1.0795^{* *}$ \\
\hline 30 & $1.0471^{* *}$ & 1.0038 & 1.0050 & 1.0151 & $1.0242^{* *}$ & $1.0347^{* *}$ & $1.0210^{* *}$ & $1.0996^{* *}$ & $1.1174^{* *}$ \\
\hline 31 & $1.0446^{* *}$ & $0.9640^{* *}$ & $0.9726^{* *}$ & $1.0784^{* *}$ & $1.0470^{* *}$ & 1.0257 & $0.9765^{* *}$ & $1.1415^{* *}$ & $1.1268^{* *}$ \\
\hline 32 & 1.0064 & $1.0349^{* *}$ & $0.9836^{*}$ & $1.0647^{* *}$ & 1.0193 & $1.0408^{* *}$ & 1.0205 & $1.1403^{* *}$ & $1.2028^{* *}$ \\
\hline 33 & $1.3115^{* *}$ & 0.9969 & $1.0468^{*}$ & $1.0806^{* *}$ & $1.0589^{* *}$ & $1.1296^{* *}$ & $1.5049^{* *}$ & $1.2945^{* *}$ & $1.7527^{* *}$ \\
\hline 34 & $1.0557^{* *}$ & 1.0092 & 1.0093 & 1.0012 & $1.0755^{* *}$ & 0.9955 & $1.0888^{* *}$ & $1.0538^{* *}$ & $1.0900^{* *}$ \\
\hline 35 & $1.0531^{* *}$ & $0.9517^{* *}$ & 1.0155 & $0.9673^{* *}$ & 1.0028 & $1.0187^{* *}$ & $0.9702^{*}$ & 0.9890 & $0.9835^{*}$ \\
\hline 36 & 1.0167 & 1.0096 & 1.0138 & 1.0059 & $1.0431^{* *}$ & $1.0491^{* *}$ & $1.0390^{* *}$ & $1.1183^{* *}$ & $1.2233^{* *}$ \\
\hline 37 & $1.0487^{* *}$ & 1.0136 & $0.9626^{* *}$ & 0.9947 & $1.0533^{* *}$ & $1.0503^{* *}$ & 0.9962 & $1.1024^{* *}$ & $1.1349^{* *}$ \\
\hline 38 & $1.0494^{* *}$ & 0.9970 & 1.0054 & $0.9591^{* *}$ & $1.0476^{* *}$ & 0.9942 & $1.0342^{* *}$ & $1.0278^{* *}$ & $1.0360^{* *}$ \\
\hline 39 & $1.0332^{*}$ & 1.0082 & 0.9919 & $1.0511^{* *}$ & 1.0232 & 0.9940 & $1.0379^{* *}$ & $1.0656^{* *}$ & $1.2206^{* *}$ \\
\hline 40 & $1.0571^{* *}$ & 1.0103 & 1.0043 & $0.9773^{* *}$ & $1.0152^{* *}$ & $1.0274^{* *}$ & $1.0742^{* *}$ & $1.0638^{* *}$ & $1.1178^{* *}$ \\
\hline 41 & $1.0533^{* *}$ & $0.9542^{* *}$ & 0.9985 & 0.9933 & 1.0142 & $1.0478^{* *}$ & 1.0058 & $1.0587^{* *}$ & $1.0741^{* *}$ \\
\hline 42 & $1.1152^{* *}$ & $0.9795^{* *}$ & $1.0534^{* *}$ & 0.9876 & $1.0634^{* *}$ & $1.0382^{* *}$ & $1.1475^{* *}$ & $1.0577^{* *}$ & $1.1736^{* *}$ \\
\hline 43 & 0.9876 & 1.0315 & 0.9877 & $1.0512^{* *}$ & $1.0565^{* *}$ & $1.0703^{* *}$ & $1.0962^{* *}$ & $1.1731^{* *}$ & $1.2807^{* *}$ \\
\hline 44 & $1.0309^{* *}$ & $1.0143^{* *}$ & 0.9954 & 0.9866 & 1.0138 & $1.0203^{* *}$ & $1.0357^{* *}$ & $1.0478^{* *}$ & $1.0563^{* *}$ \\
\hline 45 & $1.0322^{* *}$ & $0.9830^{* *}$ & 1.0086 & $1.0824^{* *}$ & $1.0755^{* *}$ & $1.0621^{* *}$ & 1.0069 & $1.1707^{* *}$ & $1.3474^{* *}$ \\
\hline 46 & $1.0423^{* *}$ & $0.9849^{* *}$ & $1.0250^{* *}$ & $0.9781^{* *}$ & $1.0448^{* *}$ & $1.0481^{* *}$ & 1.0094 & $1.0709^{* *}$ & $1.1061^{* *}$ \\
\hline 47 & $1.0292^{* *}$ & $0.9768^{* *}$ & 0.9942 & $0.9946^{*}$ & 1.0118 & $1.0481^{* *}$ & 1.0004 & $1.0536^{* *}$ & $1.1121^{* *}$ \\
\hline 48 & $0.9619^{* *}$ & 1.0046 & 1.0079 & 1.0103 & 1.0270 & $1.0787^{* *}$ & 0.9939 & $1.1527^{* *}$ & $1.2766^{* *}$ \\
\hline 49 & $1.0289^{* *}$ & 0.9923 & 1.0112 & $1.0872^{* *}$ & $1.0590^{* *}$ & $1.0353^{* *}$ & 1.0331 & $1.1861^{* *}$ & $1.2336^{* *}$ \\
\hline 50 & $0.9815^{* *}$ & 0.9983 & 0.9985 & 1.0019 & $1.0566^{* *}$ & $1.0694^{* *}$ & 0.9967 & $1.1346^{* *}$ & $1.1872^{* *}$ \\
\hline Mean & $1.0402^{* * *}$ & 0.9998 & $1.0066^{*}$ & 1.0059 & $1.0346^{* * *}$ & $1.0439^{* * *}$ & $1.0476^{* * *}$ & $1.0944^{* * *}$ & $1.1676^{\text {*** }}$ \\
\hline
\end{tabular}

$\left({ }^{*}\right),\left({ }^{* *}\right),\left({ }^{* * *}\right)$ : significant differences from unity at $10 \%, 5 \%$, and $1 \%$, respectively. In the case of the mean, significance was determined by appealing to the central limit theorem. 
Table 4: Changes in productivity, consecutive years and sub-periods

\begin{tabular}{|c|c|c|c|c|c|c|c|c|c|}
\hline$\overline{\text { Firm }}$ & $\begin{array}{c}1992 / 93 \\
\end{array}$ & $\begin{array}{l}1993 / 94 \\
\end{array}$ & 1994/95 & $\begin{array}{l}1995 / 96 \\
\end{array}$ & $\begin{array}{l}1996 / 97 \\
\end{array}$ & $1997 / 98$ & $\begin{array}{l}1992 / 95 \\
\end{array}$ & $1995 / 98$ & $\begin{array}{l}1992 / 98 \\
\end{array}$ \\
\hline 1 & $0.8943^{* *}$ & $1.0846^{* *}$ & $0.9951^{*}$ & $1.0046^{* *}$ & 1.0149 & $1.1088^{* *}$ & $0.9773^{* *}$ & $1.1875^{* *}$ & $1.0942^{* *}$ \\
\hline 2 & $1.0495^{* *}$ & $0.9717^{* *}$ & 1.0041 & $1.0140^{*}$ & $1.0328^{* *}$ & 1.0265 & 1.0267 & $1.0799^{* *}$ & $1.0753^{* *}$ \\
\hline 3 & $1.0951^{* *}$ & 1.0510 & 1.0187 & $1.1203^{* *}$ & $1.1320^{* *}$ & $1.0585^{* *}$ & $1.2005^{* *}$ & $1.3209^{* *}$ & $1.5479^{* *}$ \\
\hline 4 & 0.9881 & $0.9677^{* *}$ & $1.0300^{* *}$ & 1.0059 & $1.0635^{* *}$ & $1.1492^{* *}$ & 1.0087 & $1.2516^{* *}$ & $1.4914^{* *}$ \\
\hline 5 & $1.1268^{* *}$ & 1.0073 & $0.9569^{*}$ & $1.0755^{* *}$ & $1.0880^{* *}$ & $0.9960^{* *}$ & $1.0933^{* *}$ & $1.1709^{* *}$ & $1.4008^{* *}$ \\
\hline 6 & 1.0316 & 0.9842 & $0.9509^{*}$ & $0.9655^{* *}$ & 1.0094 & 1.0087 & 0.9653 & 1.0024 & $1.0641^{* *}$ \\
\hline 7 & $1.0866^{* *}$ & $1.1051^{* *}$ & $1.0452^{*}$ & 1.0027 & $1.0583^{* *}$ & $1.1459^{* *}$ & $1.2178^{* *}$ & $1.2508^{* *}$ & $1.5016^{* *}$ \\
\hline 8 & $0.9773^{* *}$ & $1.0506^{* *}$ & 0.9934 & $1.0411^{* *}$ & 1.0148 & $1.1007^{* *}$ & 0.9814 & $1.1645^{* *}$ & $1.1638^{* *}$ \\
\hline 9 & $1.0495^{* *}$ & $1.0498^{* *}$ & $0.9614^{* *}$ & 1.0192 & 1.0181 & $1.1101^{* *}$ & $1.0984^{* *}$ & $1.2266^{* *}$ & $1.2738^{* *}$ \\
\hline 10 & $1.0567^{* *}$ & $0.9534^{* *}$ & $1.0668^{* *}$ & $1.0421^{* *}$ & $0.9572^{* *}$ & 0.9913 & $1.0753^{* *}$ & 1.0000 & 1.0451 \\
\hline 11 & 1.0363 & $0.9327^{* *}$ & 1.0128 & 0.9989 & $1.0267^{* *}$ & $0.9961^{* *}$ & $0.9781^{* *}$ & $1.0459^{* *}$ & $0.9627^{* *}$ \\
\hline 12 & $1.0481^{*}$ & $0.9276^{* *}$ & 1.0236 & 0.9817 & $0.9820^{* *}$ & $0.9993^{* *}$ & 0.9946 & $0.9555^{* *}$ & $0.9997^{* *}$ \\
\hline 13 & $1.1371^{* *}$ & $0.9055^{* *}$ & $1.0144^{* *}$ & $0.9452^{* *}$ & $0.9905^{*}$ & 1.0067 & 1.0418 & $0.9812^{* *}$ & $0.9861^{* *}$ \\
\hline 14 & $1.0997^{* *}$ & $1.1050^{* *}$ & $0.9681^{* *}$ & $1.0437^{* *}$ & $1.0862^{* *}$ & 1.0191 & $1.0921^{* *}$ & $1.1349^{* *}$ & $1.2551^{* *}$ \\
\hline 15 & $1.0530^{* *}$ & 1.0324 & $1.0807^{* *}$ & $0.9848^{*}$ & $1.0805^{* *}$ & $1.0960^{* *}$ & $1.1569^{* *}$ & $1.1475^{* *}$ & $1.3147^{* *}$ \\
\hline 16 & $1.0824^{* *}$ & $0.9627^{* *}$ & 1.0196 & 0.9959 & $1.0453^{* *}$ & $1.0474^{* *}$ & $1.0625^{* *}$ & $1.0755^{* *}$ & $1.0946^{* *}$ \\
\hline 17 & 1.0173 & $0.9838^{*}$ & 1.0006 & $0.9767^{* *}$ & 1.0190 & 1.0193 & 1.0052 & 1.0069 & 1.0237 \\
\hline 18 & 1.0062 & $1.2533^{* *}$ & $0.9337^{* *}$ & $0.9911^{* *}$ & $1.1758^{* *}$ & $1.0963^{* *}$ & $1.1645^{* *}$ & $1.3421^{* *}$ & $1.6722^{* *}$ \\
\hline 19 & $1.0831^{* *}$ & 0.9557 & 0.9780 & 1.0205 & 1.0136 & 1.0293 & 0.9969 & $1.0823^{*}$ & $1.1204^{* *}$ \\
\hline 20 & $1.0478^{* *}$ & 1.0032 & $1.0660^{* *}$ & $0.9668^{*}$ & 0.9908 & $0.9465^{* *}$ & $1.1385^{* *}$ & $0.9511^{* *}$ & $1.0397^{*}$ \\
\hline 21 & 1.0271 & $1.0320^{* *}$ & $0.9286^{* *}$ & $1.0358^{* *}$ & 1.0210 & $1.0835^{* *}$ & 0.9909 & $1.1511^{* *}$ & $1.1668^{* *}$ \\
\hline 22 & $1.0590^{* *}$ & 0.9811 & 0.9710 & 1.0108 & 1.0337 & $1.0003^{* *}$ & 1.0427 & 1.0614 & $1.2167^{* *}$ \\
\hline 23 & 1.0671 & $0.9766^{*}$ & $0.8922^{* *}$ & $1.1125^{* *}$ & $1.0915^{* *}$ & $1.0506^{* *}$ & $0.9134^{* *}$ & $1.2830^{* *}$ & $1.1614^{* *}$ \\
\hline 24 & $0.9725^{* *}$ & $1.0404^{* *}$ & 1.0318 & $1.0641^{* *}$ & 1.0370 & $1.1321^{* *}$ & 1.0779 & $1.1850^{* *}$ & $1.4344^{* *}$ \\
\hline 25 & $0.9639^{*}$ & $0.9684^{* *}$ & $1.2003^{* *}$ & 0.9967 & $0.9979^{* *}$ & $1.1057^{* *}$ & $1.1720^{* *}$ & $1.1379^{* *}$ & $1.3983^{* *}$ \\
\hline 26 & $0.9813^{*}$ & 1.0137 & $1.0819^{* *}$ & $1.0377^{* *}$ & $1.0418^{*}$ & 1.0210 & $1.0474^{* *}$ & $1.1198^{* *}$ & $1.2175^{* *}$ \\
\hline 27 & 0.9932 & $0.9748^{*}$ & $0.9211^{* *}$ & 1.0010 & 1.0188 & $1.0718^{* *}$ & $0.8873^{* *}$ & $1.0979^{* *}$ & $1.0500^{*}$ \\
\hline 28 & $1.0603^{* *}$ & $1.0761^{* *}$ & $1.0036^{* *}$ & 0.9960 & $1.0636^{* *}$ & $1.0626^{* *}$ & $1.1328^{* *}$ & $1.1071^{* *}$ & $1.2543^{* *}$ \\
\hline 29 & $1.0342^{* *}$ & 0.9955 & $0.9675^{* *}$ & $1.0136^{*}$ & 1.0163 & 1.0137 & 0.9936 & $1.0619^{* *}$ & $1.0775^{* *}$ \\
\hline 30 & $1.0847^{* *}$ & $1.0449^{* *}$ & $1.0732^{* *}$ & 1.0084 & $0.9542^{* *}$ & $1.0575^{* *}$ & $1.1759^{* *}$ & 1.0401 & $1.2173^{* *}$ \\
\hline 31 & $1.0449^{*}$ & 0.9670 & $1.0311^{* *}$ & $1.1522^{* *}$ & $1.0470^{* *}$ & 1.0257 & $1.0388^{* *}$ & $1.2196^{* *}$ & $1.2808^{* *}$ \\
\hline 32 & 0.9824 & $1.0946^{* *}$ & 0.9806 & $1.0680^{* *}$ & 1.0193 & 1.0052 & $1.0505^{* *}$ & $1.1048^{*}$ & $1.1994^{* *}$ \\
\hline 33 & $1.3115^{* *}$ & 0.9969 & $1.0468^{*}$ & $1.0806^{* *}$ & $1.0589^{* *}$ & $1.1296^{* *}$ & $1.5049^{* *}$ & $1.2945^{* *}$ & $1.7527^{* *}$ \\
\hline 34 & $1.0532^{* *}$ & 0.9836 & 1.0067 & $1.0250^{* *}$ & $1.0832^{* *}$ & 0.9955 & 1.0559 & $1.0866^{* *}$ & $1.0900^{* *}$ \\
\hline 35 & $1.0478^{*}$ & 0.9699 & $0.9383^{* *}$ & $0.9355^{* *}$ & $0.9537^{* *}$ & $1.0312^{* *}$ & $0.9090^{* *}$ & $0.9208^{* *}$ & $0.8579^{* *}$ \\
\hline 36 & 0.9914 & $1.0632^{* *}$ & $1.0483^{* *}$ & $1.0697^{* *}$ & 1.0069 & $1.0418^{*}$ & $1.1033^{* *}$ & $1.1400^{* *}$ & $1.3243^{* *}$ \\
\hline 37 & 1.0009 & $1.0517^{* *}$ & 1.0020 & 1.0157 & $1.1147^{* *}$ & $0.9847^{* *}$ & 1.0270 & $1.1170^{* *}$ & $1.1856^{* *}$ \\
\hline 38 & 1.0106 & 0.9949 & 1.0191 & 0.9742 & $1.0916^{* *}$ & $0.9450^{* *}$ & 1.0073 & 1.0348 & 1.0159 \\
\hline 39 & 1.0332 & 1.0082 & 0.9919 & $1.0511^{* *}$ & 1.0232 & 0.9923 & 1.0379 & $1.0656^{* *}$ & $1.2206^{* *}$ \\
\hline 40 & $0.9226^{* *}$ & $1.0570^{* *}$ & $0.9350^{* *}$ & 0.9941 & $1.0839^{* *}$ & $1.0969^{* *}$ & $0.9131^{* *}$ & $1.2333^{* *}$ & $1.1016^{* *}$ \\
\hline 41 & $0.9568^{* *}$ & $1.0158^{* *}$ & 1.0145 & $0.9406^{* *}$ & $0.9890^{*}$ & $1.0615^{* *}$ & 0.9883 & $0.9903^{* *}$ & $0.9872^{* *}$ \\
\hline 42 & $1.1488^{* *}$ & $0.9592^{* *}$ & $1.0611^{* *}$ & 1.0012 & $1.0106^{* *}$ & 1.0102 & $1.1659^{* *}$ & $0.9916^{* *}$ & $1.1179^{*}$ \\
\hline 43 & 0.9876 & 1.0112 & 0.9798 & 1.0426 & 1.0197 & $1.1496^{* *}$ & 1.0663 & $1.2060^{* *}$ & $1.2807^{* *}$ \\
\hline 44 & $1.0496^{* *}$ & $0.9568^{* *}$ & $0.9492^{* *}$ & $1.0198^{*}$ & 1.0037 & $1.0480^{* *}$ & $0.9486^{* *}$ & $1.1015^{* *}$ & 1.0170 \\
\hline 45 & 1.0271 & $1.0498^{* *}$ & $1.1114^{* *}$ & $1.0642^{*}$ & $1.0841^{* *}$ & $1.0717^{* *}$ & $1.1788^{* *}$ & $1.1707^{* *}$ & $1.5775^{* *}$ \\
\hline 46 & $1.0677^{* *}$ & 1.0223 & 1.0327 & $1.0263^{* *}$ & 1.0319 & $1.0457^{* *}$ & $1.0812^{* *}$ & $1.1072^{* *}$ & $1.2250^{* *}$ \\
\hline 47 & 1.0067 & 0.9730 & $0.9696^{*}$ & $0.9273^{* *}$ & $1.0314^{*}$ & $1.0848^{* *}$ & $0.9506^{* *}$ & 1.0362 & 1.0393 \\
\hline 48 & 0.9619 & 1.0046 & $0.9025^{* *}$ & 0.9929 & 1.0297 & $1.0911^{* *}$ & $0.8900^{* *}$ & $1.1486^{* *}$ & 1.1391 \\
\hline 49 & $0.9553^{* *}$ & $1.0334^{* *}$ & $1.0575^{* *}$ & $1.0872^{* *}$ & $1.0590^{* *}$ & $1.0353^{* *}$ & 1.0447 & $1.1861^{* *}$ & $1.2475^{* *}$ \\
\hline 50 & $1.0478^{* *}$ & $1.0207^{*}$ & $0.9394^{* *}$ & $1.0423^{* *}$ & $1.0923^{* *}$ & $1.0694^{* *}$ & 1.0235 & $1.2202^{* *}$ & $1.3111^{* *}$ \\
\hline Mean & $1.0344^{* * *}$ & 1.0109 & 1.0026 & $1.0186^{* * *}$ & $1.0372^{* * *}$ & $1.0481^{* * *}$ & $1.0491^{* * *}$ & $1.1156^{* * *}$ & $1.1920^{* * *}$ \\
\hline
\end{tabular}

$\left({ }^{*}\right),\left({ }^{* *}\right),\left({ }^{* *}\right)$ : significant differences from unity at $10 \%, 5 \%$, and $1 \%$, respectively. In the case of the mean, significance was determined by appealing to the central limit theorem. 
took place at rates exceeding $1 \%$ only in 1993/94 and 1995/96. There are even deteriorations in $1992 / 93$ and 1994/95, although the overall tendency (1997/98) was to increase.

However, individual scrutiny shows that there are remarkable disparities between the three indices. For instance, firm \#1 underwent substantial productivity decline from 1992 to 1993 due to falling behind "best practice" (or catching up with "worst practice"); in fact, there was technical progress of $3.68 \%$. On the other hand, and also in 1992/93, firm \#50 experienced productivity growth (4.78\%) due to an improvement in efficiency, despite technical regress (1.85\%).

Our results coincide with those of Pastor (1995), but differ from those of Grifell-Tatjé and Lovell (1996). They also coincide with those of Berg et al. (1992a), who find productivity regress prior to deregulation, but rapid productivity growth after deregulation - although we do not analyze the pre-deregulation era. However, as stated by Grifell-Tatjé and Lovell (1996) it is perhaps surprising, and hopefully temporary, but not unusual that a productivity decline should accompany deregulation. Some evidence was reported by Bauer et al. (1993), or Humphrey (1993). But more recent evidence, employing linear programming techniques such as ours, found productivity decline (Wheelock and Wilson, 1999). On the other hand, our results are coincidental with the recent study by Mukherjee et al. (2001) who also through linear programming techniques, find productivity growth. As stated by these authors, a key difference may lie in the identification of outputs. We also think that the evolution of savings banks' product mixes may have played a non-negligible role in this process. In fact, one of the outputs $\left(y_{3}\right.$, non-traditional output) includes items in an attempt to reflect the financial innovation performed by most savings banks, which in most cases has enabled them to increase their revenues.

In addition, our bootstrap method allows assessment of the "null hypothesis" of insignificant efficiency change, technical change, and productivity growth/decline, which predicts that the corresponding measures are not statistically different from unity. Resampling has been carried out for $B=1000$-i.e., we have 1000 pseudo-samples. We provide results for both $90 \%$ and $95 \%$ confidence intervals. They allow assessment of the null hypothesis of no efficiency change, technical change, or productivity growth/decline which indicates that the corresponding measures are not statistically different from unity. The interpretation is straightforward. In the $95 \%$ confidence interval case, if it contains the unity, then the corresponding measure is not significantly different from one at the $5 \%$ significance level, i.e., it is not possible to conclude that changes occurred in efficiency, technology, or productivity. In contrast, when the interval excludes the unity, one can conclude with $95 \%$ confidence that the corresponding measure is significantly different from unity. An analogous interpretation is applicable for the $90 \%$ confidence interval, and conclusions must be drawn at a $10 \%$ significance level.

One conclusion from the original results is that a number of savings banks had productivity regress in all periods. Specifically, table 4 shows that positive productivity change occurred in $36,27,28,33,42$, and 41 cases for periods 1992/93, 1993/94, 1994/95, 1995/96, 1996/97 and 1997/98, respectively-for the remainder, productivity decline occurred. If we consider longer periods, tendencies are more emphasized, as productivity growth occurs in 34, 43, and 45 cases, for periods 1992/95, 1995/98, and 1992/98, respectively. Put other way, considering the entire period 1992/98, all other institutions underwent productivity growth with the exception of five firms. However, there are several cases in which the positive changes 
are not significant. For instance, in 1992/93, out of the 14 firms which suffered productivity decline (i.e., negative values), only 6 (firms \#1, 8, 24, 40, 41 and 49) differed from unity at 5\% significance level, 2 (firms \#25 and 26) differed from unity at 10\% significance level and, in 6 cases (firms \#4, 27, 32, 36, 43 and 48), productivity decline was not statistically significant. Similar trends hold for the 36 firms which underwent productivity growth, out of which productivity growth is statistically significant at $5 \%$ on 21 occasions, and at $1 \%$ in the other four cases. In the remaining 11 firms productivity growth estimates are not significant and hence cannot be determined.

Differences in conclusions between the original and the bootstrap results are more evident when scrutinizing certain particular cases. For instance, from the original results we would conclude that firm \#19 in 1993/94 had a productivity decline amounting to about 4.4\% (see table 4); in contrast, firm \#15 experienced productivity growth amounting to about $3.2 \%$. However, the conclusion from the bootstrap results is that neither of these two savings banks had a change in productivity significantly different from unity.

Turning to the results for efficiency change (table 2) we note that three firms were efficient ("bestpractice") in all time periods (firms \#3, 6, 33) as revealed by values of unity between all successive pairs of years and sub-periods. Our bootstrap reveals an additional bank (\#39) to be efficient in all years, as the figures diverging from unity are not significant. In addition, if we only consider the non-consecutive years analysis $(1992 / 95,1995 / 98,1992 / 98)$, there are two additional firms with no efficiency changes (firms \#20, 39), and a further three firms whose efficiency gains or losses are not significant (firms \#10, 34, 49). We also observe that significant changes in efficiency occur mainly for the whole period 1992/98. In other periods (for instance, 1992/95) there are efficiency changes for most firms, although most of them are not significant. In sum, for the consecutive pairs of years, out of the 234 estimates that showed efficiency gain or loss, only 135 and 17 differed significantly from unity at 5\% and $10 \%$ significance levels, respectively. When considering longer periods, these percentages are much higher, particularly in 1992/98.

Finally, for the technical change component (table 3), a negative shift in technology is obtained for 77 firms in the original results for the consecutive years, out of which our bootstrap method recognized only 31 cases to be significantly different from unity at $5 \%$, and 8 at $10 \%$. For the remainder, technical regress was not statistically significant. The positive change occurs more often, in 221 instances - out of the 300 entries for consecutive years-, but only 132 are statistically different from unity at 5\%, and 9 at $10 \%$. Again, for the remainder, technical progress is not significant.

However, for the sub-periods results vary to a certain extent. Considering the entire 1992/98 period (last column of table 3), technical change is positive for all firms except firms \#16 and 35. The former experiences insignificant technical regress, and the latter experiences significant technical regress, although only at $10 \%$ significance level. A further three firms experience technical progress, although at insignificant rates (firms \#11, 20, 27). These changes are decomposable into two sub-periods. In the initial 1992/95 post-deregulation period, the mean for technical progress is lower than in 1995/98 (1.0476 vs. 1.0944). The former was the period before which the bulk of mergers had just occurred, hence one might expect technology to improve slowly. In fact, significant (at 5\%) technical progress is found only for 26 firms. In 1995/98 this pattern is present in 41 instances. 
Therefore, according to the above statements, one may easily conclude that comparisons of production units based on the original point estimates should be made with caution. In many instances, the productivity, efficiency, and technical change estimates deviate from unity at insignificant levels, which clearly lowers the extent to which our conclusions are convincing. In other words, as suggested by Simar and Wilson (1999a), "as with any estimator, it is not enough to know whether the Malmquist productivity index indicates increases or decreases in productivity, but whether the indicated changes are significant in a statistical sense".

\subsection{Productive efficiency}

Tables 5-7 show results for the bootstrap of efficiency scores for years 1992, 1995, and 1998 - for the sake of brevity. ${ }^{14}$ A summary is presented in table 8, which shows that efficiency at industry level (mean efficiency) enhanced slightly over the sample period - although notable ups and downs also occurred. The result coincides with what may a priori be expected in an industry in which deregulation has already taken place. However, the industry is still going through important changes.

Out of the 50 savings banks in the original sample, an average of 15 banks were found to operate on the best practice frontier $\left(\hat{\theta}_{i}=1\right)$. As stated by Ferrier and Hirschberg (1997), this result does not supply much information to decision makers as it is not possible to distinguish between the performances of many of the banks. In these circumstances, our bootstrap procedure turns out to be a very useful tool.

Columns 2-5 in tables 5, 6 and 7 provide the original DEA efficiency score, the bootstrap bias estimate, the bias-corrected estimate, and the median of the bootstrapped values, respectively. In addition, columns 6-9 provide two types of $95 \%$ confidence intervals for the bias-corrected efficiency scores, although results are quite similar. Specifically, columns 6 and 7 are the confidence interval based on the bias-correction formula in (19), whereas columns 8 and 9 were computed according to Efron and Tibshirani (1993). All results in those tables were computed considering the smoothing parameters displayed in figure 1.

These results reveal the sensitivity of the efficiency measures with respect to sampling variation. The bias-corrected estimates $\left(\tilde{\theta}_{i}\right)$ in column 4 reveal that differences in measured efficiency are of a different magnitude than when original efficiency scores $\left(\hat{\theta}_{i}\right)$ are considered. ${ }^{15}$ Specifically, we observe that for some firms efficiency enhances, whereas for others it deteriorates. In 1992 (table 5$)$ there are 7 firms (\#9, $17,32,38,41,42$ and 49) for which the bias-corrected estimate is higher than the original one. ${ }^{16}$ On the other hand, there are many others for which efficiency declines. Among these, there are some cases in which efficiency deteriorates severely, by more than 0.1 (firms \#4, 5, 16, 18, 30, 45), or by more than 0.05 (firms \#2, 10, 14, 15, 23, 24, 31, 36, 37, 50). In the case of the originally-efficient firms (with $\hat{\theta}_{i}=1.000$ ) efficiency improves; obviously, there is no economic meaning for this, and we should interpret it as if these indices were one. However, we also have additional statistical information on these firms, as confidence intervals are constructed. We will examine this below.

\footnotetext{
${ }^{14}$ Results for all years are available from the authors upon request.

${ }^{15}$ However, as stated by González and Miles (2002), results should be interpreted with care, as values less than zero or greater than one are statistically valid and reflect the efficiency level of a firm, but they have no economic meaning-efficiency scores are bounded between zero and one.

${ }^{16}$ Those firms with bias-corrected efficiency estimate greater than one are interpreted as if it were one.
} 
Table 5: Bootstrap of efficiency scores, 1992

\begin{tabular}{|c|c|c|c|c|c|c|c|c|}
\hline \multirow[b]{2}{*}{ Firm } & \multirow[b]{2}{*}{$\hat{\theta}_{i}$} & \multirow[b]{2}{*}{$\operatorname{Bias}_{i}$} & \multirow[b]{2}{*}{$\tilde{\theta}_{i}$} & \multirow[b]{2}{*}{ Median of $\tilde{\theta}_{i}^{*}$} & $2.5 \%$ & $97.5 \%$ & $2.5 \%$ & $97.5 \%$ \\
\hline & & & & & \multicolumn{2}{|c|}{ Bias corrected } & \multicolumn{2}{|c|}{ Centered on $\tilde{\theta}_{i}$} \\
\hline 1 & 1.0000 & -0.0363 & 1.0363 & 1.0643 & 0.9151 & 1.0726 & 0.8763 & 1.0726 \\
\hline 2 & 0.8934 & 0.0517 & 0.8417 & 0.8563 & 0.7021 & 0.8965 & 0.6871 & 0.8965 \\
\hline 3 & 1.0000 & -0.0161 & 1.0161 & 1.0323 & 0.9072 & 1.0323 & 0.8532 & 1.0323 \\
\hline 4 & 0.8571 & 0.1063 & 0.7508 & 0.7777 & 0.6151 & 0.7874 & 0.5917 & 0.7874 \\
\hline 5 & 0.8431 & 0.1250 & 0.7181 & 0.7474 & 0.5925 & 0.7500 & 0.5426 & 0.7500 \\
\hline 6 & 1.0000 & -0.0001 & 1.0001 & 1.0001 & 0.9996 & 1.0001 & 0.9892 & 1.0001 \\
\hline 7 & 0.9531 & 0.0087 & 0.9444 & 0.9681 & 0.8116 & 0.9826 & 0.7867 & 0.9826 \\
\hline 8 & 0.9162 & 0.0354 & 0.8807 & 0.8993 & 0.7438 & 0.9292 & 0.7286 & 0.9292 \\
\hline 9 & 0.9597 & -0.0009 & 0.9606 & 0.9855 & 0.8321 & 1.0018 & 0.8034 & 1.0018 \\
\hline 10 & 0.8561 & 0.0860 & 0.7700 & 0.7822 & 0.6342 & 0.8280 & 0.6224 & 0.8280 \\
\hline 11 & 1.0000 & -0.0445 & 1.0445 & 1.0666 & 0.9000 & 1.0890 & 0.8762 & 1.0890 \\
\hline 12 & 1.0000 & -0.0288 & 1.0288 & 1.0577 & 0.9060 & 1.0577 & 0.8403 & 1.0577 \\
\hline 13 & 0.9215 & 0.0257 & 0.8957 & 0.9127 & 0.7630 & 0.9485 & 0.7397 & 0.9485 \\
\hline 14 & 0.8778 & 0.0697 & 0.8081 & 0.8229 & 0.6789 & 0.8606 & 0.6622 & 0.8606 \\
\hline 15 & 0.9016 & 0.0611 & 0.8405 & 0.8695 & 0.7049 & 0.8777 & 0.6732 & 0.8777 \\
\hline 16 & 0.7952 & 0.1482 & 0.6470 & 0.6631 & 0.5047 & 0.7035 & 0.4838 & 0.7035 \\
\hline 17 & 0.9770 & -0.0304 & 1.0075 & 1.0254 & 0.8694 & 1.0609 & 0.8494 & 1.0609 \\
\hline 18 & 0.7764 & 0.1845 & 0.5919 & 0.6192 & 0.4688 & 0.6311 & 0.4422 & 0.6311 \\
\hline 19 & 0.9550 & 0.0017 & 0.9533 & 0.9759 & 0.8206 & 0.9967 & 0.7969 & 0.9967 \\
\hline 20 & 1.0000 & -0.0041 & 1.0041 & 1.0082 & 0.9475 & 1.0082 & 0.8811 & 1.0082 \\
\hline 21 & 0.9367 & 0.0087 & 0.9279 & 0.9434 & 0.7890 & 0.9825 & 0.7614 & 0.9825 \\
\hline 22 & 1.0000 & -0.0083 & 1.0083 & 1.0166 & 0.9226 & 1.0166 & 0.8751 & 1.0166 \\
\hline 23 & 0.8708 & 0.0917 & 0.7790 & 0.8049 & 0.6482 & 0.8166 & 0.6167 & 0.8166 \\
\hline 24 & 0.9081 & 0.0552 & 0.8528 & 0.8827 & 0.7192 & 0.8896 & 0.6769 & 0.8896 \\
\hline 25 & 0.9248 & 0.0373 & 0.8875 & 0.9142 & 0.7445 & 0.9255 & 0.7160 & 0.9255 \\
\hline 26 & 0.9179 & 0.0261 & 0.8917 & 0.9089 & 0.7488 & 0.9477 & 0.7339 & 0.9477 \\
\hline 27 & 1.0000 & -0.0078 & 1.0078 & 1.0156 & 0.9297 & 1.0156 & 0.8660 & 1.0156 \\
\hline 28 & 0.9458 & 0.0001 & 0.9457 & 0.9587 & 0.8136 & 0.9998 & 0.8003 & 0.9998 \\
\hline 29 & 1.0000 & -0.0244 & 1.0244 & 1.0488 & 0.9054 & 1.0488 & 0.8407 & 1.0488 \\
\hline 30 & 0.8287 & 0.1118 & 0.7169 & 0.7318 & 0.5826 & 0.7763 & 0.5699 & 0.7763 \\
\hline 31 & 0.8797 & 0.0777 & 0.8020 & 0.8254 & 0.6614 & 0.8446 & 0.6318 & 0.8446 \\
\hline 32 & 0.9685 & -0.0156 & 0.9842 & 1.0065 & 0.8478 & 1.0312 & 0.8262 & 1.0312 \\
\hline 33 & 1.0000 & -0.0006 & 1.0006 & 1.0012 & 0.9982 & 1.0012 & 0.9293 & 1.0012 \\
\hline 34 & 1.0000 & -0.0350 & 1.0350 & 1.0628 & 0.9046 & 1.0701 & 0.8818 & 1.0701 \\
\hline 35 & 0.9179 & 0.0455 & 0.8724 & 0.9035 & 0.7307 & 0.9090 & 0.6956 & 0.9090 \\
\hline 36 & 0.8855 & 0.0696 & 0.8159 & 0.8352 & 0.6746 & 0.8608 & 0.6432 & 0.8608 \\
\hline 37 & 0.8660 & 0.0754 & 0.7906 & 0.8063 & 0.6517 & 0.8491 & 0.6384 & 0.8491 \\
\hline 38 & 0.9693 & -0.0279 & 0.9971 & 1.0104 & 0.8608 & 1.0557 & 0.8456 & 1.0557 \\
\hline 39 & 1.0000 & -0.0321 & 1.0321 & 1.0638 & 0.9090 & 1.0641 & 0.8662 & 1.0641 \\
\hline 40 & 0.9396 & 0.0130 & 0.9266 & 0.9481 & 0.7911 & 0.9740 & 0.7661 & 0.9740 \\
\hline 41 & 0.9469 & -0.0077 & 0.9546 & 0.9645 & 0.8200 & 1.0154 & 0.8052 & 1.0154 \\
\hline 42 & 0.9709 & -0.0145 & 0.9853 & 1.0126 & 0.8427 & 1.0289 & 0.8182 & 1.0289 \\
\hline 43 & 1.0000 & -0.0005 & 1.0005 & 1.0010 & 0.9995 & 1.0010 & 0.9482 & 1.0008 \\
\hline 44 & 0.9093 & 0.0335 & 0.8758 & 0.8891 & 0.7399 & 0.9329 & 0.7194 & 0.9329 \\
\hline 45 & 0.8541 & 0.1021 & 0.7520 & 0.7726 & 0.6239 & 0.7958 & 0.6032 & 0.7958 \\
\hline 46 & 0.8005 & 0.1551 & 0.6454 & 0.6653 & 0.5223 & 0.6898 & 0.4902 & 0.6898 \\
\hline 47 & 0.9483 & 0.0049 & 0.9434 & 0.9639 & 0.8057 & 0.9903 & 0.7749 & 0.9903 \\
\hline 48 & 1.0000 & -0.0123 & 1.0123 & 1.0246 & 0.9059 & 1.0246 & 0.8633 & 1.0246 \\
\hline 49 & 0.9889 & -0.0238 & 1.0127 & 1.0412 & 0.8775 & 1.0477 & 0.8277 & 1.0477 \\
\hline 50 & 0.9055 & 0.0563 & 0.8491 & 0.8767 & 0.7194 & 0.8874 & 0.6889 & 0.8874 \\
\hline
\end{tabular}


Table 6: Bootstrap of efficiency scores, 1995

\begin{tabular}{|c|c|c|c|c|c|c|c|c|}
\hline \multirow[b]{2}{*}{ Firm } & \multirow[b]{2}{*}{$\hat{\theta}_{i}$} & \multirow[b]{2}{*}{$\operatorname{Bias}_{i}$} & \multirow[b]{2}{*}{$\tilde{\theta}_{i}$} & \multirow[b]{2}{*}{ Median of $\tilde{\theta}_{i}^{*}$} & $2.5 \%$ & $97.5 \%$ & $2.5 \%$ & $97.5 \%$ \\
\hline & & & & & \multicolumn{2}{|c|}{ Bias corrected } & \multicolumn{2}{|c|}{ Centered on $\tilde{\theta}_{i}$} \\
\hline 1 & 0.8809 & 0.0794 & 0.8015 & 0.8270 & 0.6660 & 0.8413 & 0.6291 & 0.8413 \\
\hline 2 & 0.8628 & 0.0920 & 0.7709 & 0.7921 & 0.6348 & 0.8160 & 0.6117 & 0.8160 \\
\hline 3 & 1.0000 & -0.0136 & 1.0136 & 1.0271 & 0.9129 & 1.0271 & 0.8424 & 1.0271 \\
\hline 4 & 0.8506 & 0.1068 & 0.7438 & 0.7681 & 0.6107 & 0.7864 & 0.5783 & 0.7864 \\
\hline 5 & 0.9532 & -0.0018 & 0.9550 & 0.9726 & 0.8164 & 1.0036 & 0.7867 & 1.0036 \\
\hline 6 & 1.0000 & 0.0000 & 1.0000 & 1.0000 & 1.0000 & 1.0000 & 0.9958 & 1.0000 \\
\hline 7 & 1.0000 & -0.0021 & 1.0021 & 1.0042 & 0.9627 & 1.0042 & 0.8950 & 1.0042 \\
\hline 8 & 0.8928 & 0.0548 & 0.8379 & 0.8567 & 0.7085 & 0.8904 & 0.6679 & 0.8904 \\
\hline 9 & 0.9806 & -0.0130 & 0.9936 & 1.0236 & 0.8698 & 1.0261 & 0.8246 & 1.0261 \\
\hline 10 & 0.8566 & 0.0900 & 0.7665 & 0.7823 & 0.6357 & 0.8199 & 0.6023 & 0.8199 \\
\hline 11 & 0.9191 & 0.0348 & 0.8843 & 0.9043 & 0.7436 & 0.9305 & 0.7120 & 0.9305 \\
\hline 12 & 1.0000 & -0.0458 & 1.0458 & 1.0619 & 0.9144 & 1.0917 & 0.8908 & 1.0917 \\
\hline 13 & 0.9262 & 0.0284 & 0.8978 & 0.9178 & 0.7628 & 0.9432 & 0.7275 & 0.9432 \\
\hline 14 & 0.8918 & 0.0630 & 0.8288 & 0.8497 & 0.6870 & 0.8741 & 0.6549 & 0.8741 \\
\hline 15 & 1.0000 & -0.0478 & 1.0478 & 1.0673 & 0.9182 & 1.0956 & 0.8777 & 1.0956 \\
\hline 16 & 0.8202 & 0.1289 & 0.6913 & 0.7086 & 0.5593 & 0.7421 & 0.5280 & 0.7421 \\
\hline 17 & 0.9272 & 0.0187 & 0.9085 & 0.9233 & 0.7756 & 0.9627 & 0.7495 & 0.9627 \\
\hline 18 & 0.8926 & 0.0612 & 0.8314 & 0.8503 & 0.6909 & 0.8776 & 0.6606 & 0.8776 \\
\hline 19 & 1.0000 & -0.0514 & 1.0514 & 1.0683 & 0.9144 & 1.1029 & 0.8868 & 1.1029 \\
\hline 20 & 1.0000 & -0.0043 & 1.0043 & 1.0086 & 0.9421 & 1.0086 & 0.8655 & 1.0086 \\
\hline 21 & 0.9283 & 0.0207 & 0.9075 & 0.9256 & 0.7651 & 0.9585 & 0.7426 & 0.9585 \\
\hline 22 & 1.0000 & -0.0236 & 1.0236 & 1.0471 & 0.8938 & 1.0471 & 0.8498 & 1.0471 \\
\hline 23 & 0.7631 & 0.1911 & 0.5720 & 0.5936 & 0.4418 & 0.6179 & 0.4077 & 0.6179 \\
\hline 24 & 0.8873 & 0.0735 & 0.8138 & 0.8370 & 0.6771 & 0.8530 & 0.6507 & 0.8530 \\
\hline 25 & 1.0000 & -0.0179 & 1.0179 & 1.0357 & 0.9074 & 1.0357 & 0.8301 & 1.0357 \\
\hline 26 & 0.9576 & -0.0039 & 0.9614 & 0.9793 & 0.8289 & 1.0077 & 0.8014 & 1.0077 \\
\hline 27 & 0.9728 & -0.0258 & 0.9986 & 1.0137 & 0.8574 & 1.0516 & 0.8348 & 1.0516 \\
\hline 28 & 0.9004 & 0.0650 & 0.8354 & 0.8682 & 0.7111 & 0.8700 & 0.6490 & 0.8700 \\
\hline 29 & 0.9684 & -0.0139 & 0.9823 & 1.0027 & 0.8482 & 1.0278 & 0.8137 & 1.0278 \\
\hline 30 & 0.9544 & -0.0041 & 0.9586 & 0.9751 & 0.8299 & 1.0083 & 0.7954 & 1.0083 \\
\hline 31 & 0.9359 & 0.0172 & 0.9187 & 0.9401 & 0.7829 & 0.9657 & 0.7486 & 0.9657 \\
\hline 32 & 0.9970 & -0.0470 & 1.0440 & 1.0600 & 0.9070 & 1.0940 & 0.8777 & 1.0940 \\
\hline 33 & 1.0000 & -0.0001 & 1.0001 & 1.0002 & 0.9999 & 1.0002 & 0.9896 & 1.0001 \\
\hline 34 & 0.9697 & -0.0071 & 0.9769 & 1.0047 & 0.8482 & 1.0142 & 0.7932 & 1.0142 \\
\hline 35 & 0.8600 & 0.0987 & 0.7613 & 0.7842 & 0.6309 & 0.8026 & 0.5897 & 0.8026 \\
\hline 36 & 0.9404 & 0.0192 & 0.9212 & 0.9451 & 0.7981 & 0.9617 & 0.7597 & 0.9617 \\
\hline 37 & 0.8929 & 0.0621 & 0.8308 & 0.8487 & 0.6991 & 0.8759 & 0.6679 & 0.8759 \\
\hline 38 & 0.9441 & 0.0051 & 0.9389 & 0.9591 & 0.7953 & 0.9897 & 0.7718 & 0.9897 \\
\hline 39 & 1.0000 & -0.0128 & 1.0128 & 1.0256 & 0.9229 & 1.0256 & 0.8579 & 1.0256 \\
\hline 40 & 0.7987 & 0.1474 & 0.6513 & 0.6665 & 0.5052 & 0.7051 & 0.4821 & 0.7051 \\
\hline 41 & 0.9304 & 0.0155 & 0.9149 & 0.9276 & 0.7813 & 0.9689 & 0.7643 & 0.9689 \\
\hline 42 & 0.9864 & -0.0284 & 1.0148 & 1.0433 & 0.8772 & 1.0567 & 0.8466 & 1.0567 \\
\hline 43 & 0.9727 & -0.0118 & 0.9845 & 1.0142 & 0.8422 & 1.0236 & 0.8067 & 1.0236 \\
\hline 44 & 0.8328 & 0.1156 & 0.7172 & 0.7342 & 0.5758 & 0.7688 & 0.5515 & 0.7688 \\
\hline 45 & 1.0000 & -0.0350 & 1.0350 & 1.0634 & 0.9061 & 1.0700 & 0.8663 & 1.0700 \\
\hline 46 & 0.8575 & 0.0939 & 0.7636 & 0.7812 & 0.6296 & 0.8122 & 0.5999 & 0.8122 \\
\hline 47 & 0.9011 & 0.0444 & 0.8567 & 0.8703 & 0.7232 & 0.9112 & 0.6999 & 0.9112 \\
\hline 48 & 0.8955 & 0.0609 & 0.8346 & 0.8532 & 0.7031 & 0.8782 & 0.6724 & 0.8782 \\
\hline 49 & 1.0000 & -0.0315 & 1.0315 & 1.0631 & 0.8989 & 1.0631 & 0.8660 & 1.0631 \\
\hline 50 & 0.9298 & 0.0232 & 0.9066 & 0.9266 & 0.7725 & 0.9536 & 0.7487 & 0.9536 \\
\hline
\end{tabular}


Table 7: Bootstrap of efficiency scores, 1998

\begin{tabular}{|c|c|c|c|c|c|c|c|c|}
\hline \multirow[b]{2}{*}{ Firm } & \multirow[b]{2}{*}{$\hat{\theta}_{i}$} & \multirow[b]{2}{*}{$\operatorname{Bias}_{i}$} & \multirow[b]{2}{*}{$\tilde{\theta}_{i}$} & \multirow[b]{2}{*}{ Median of $\tilde{\theta}_{i}^{*}$} & $2.5 \%$ & $97.5 \%$ & $2.5 \%$ & $97.5 \%$ \\
\hline & & & & & \multicolumn{2}{|c|}{ Bias corrected } & \multicolumn{2}{|c|}{ Centered on $\theta_{i}$} \\
\hline 1 & 0.9803 & -0.0201 & 1.0004 & 1.0208 & 0.8851 & 1.0401 & 0.8476 & 1.0401 \\
\hline 2 & 0.9228 & 0.0393 & 0.8835 & 0.9036 & 0.7702 & 0.9213 & 0.7268 & 0.9213 \\
\hline 3 & 1.0000 & -0.0003 & 1.0003 & 1.0006 & 1.0006 & 1.0006 & 0.9498 & 0.9814 \\
\hline 4 & 0.9277 & 0.0395 & 0.8883 & 0.9163 & 0.7696 & 0.9211 & 0.7339 & 0.9211 \\
\hline 5 & 0.9113 & 0.0576 & 0.8537 & 0.8815 & 0.7387 & 0.8848 & 0.6929 & 0.8848 \\
\hline 6 & 1.0000 & 0.0000 & 1.0000 & 1.0000 & 1.0000 & 1.0000 & 0.9997 & 1.0000 \\
\hline 7 & 1.0000 & -0.0011 & 1.0011 & 1.0022 & 0.9873 & 1.0022 & 0.9269 & 1.0022 \\
\hline 8 & 0.9779 & -0.0188 & 0.9967 & 1.0169 & 0.8846 & 1.0376 & 0.8522 & 1.0376 \\
\hline 9 & 1.0000 & -0.0014 & 1.0014 & 1.0027 & 0.9830 & 1.0027 & 0.9172 & 1.0027 \\
\hline 10 & 0.8647 & 0.0921 & 0.7726 & 0.7953 & 0.6464 & 0.8159 & 0.6221 & 0.8159 \\
\hline 11 & 0.9504 & 0.0101 & 0.9404 & 0.9603 & 0.8362 & 0.9798 & 0.7928 & 0.9798 \\
\hline 12 & 0.8889 & 0.0754 & 0.8135 & 0.8360 & 0.7019 & 0.8492 & 0.6575 & 0.8492 \\
\hline 13 & 0.8356 & 0.1225 & 0.7132 & 0.7300 & 0.5831 & 0.7551 & 0.5661 & 0.7551 \\
\hline 14 & 0.9609 & 0.0078 & 0.9531 & 0.9802 & 0.8475 & 0.9844 & 0.8052 & 0.9844 \\
\hline 15 & 1.0000 & -0.0031 & 1.0031 & 1.0063 & 0.9590 & 1.0063 & 0.8986 & 1.0063 \\
\hline 16 & 0.8758 & 0.0822 & 0.7936 & 0.8148 & 0.6762 & 0.8356 & 0.6405 & 0.8356 \\
\hline 17 & 0.9364 & 0.0264 & 0.9100 & 0.9334 & 0.7868 & 0.9472 & 0.7508 & 0.9472 \\
\hline 18 & 0.9639 & 0.0051 & 0.9588 & 0.9872 & 0.8470 & 0.9898 & 0.7985 & 0.9898 \\
\hline 19 & 1.0000 & -0.0313 & 1.0313 & 1.0591 & 0.9133 & 1.0627 & 0.8845 & 1.0627 \\
\hline 20 & 1.0000 & -0.0061 & 1.0061 & 1.0122 & 0.9473 & 1.0122 & 0.8860 & 1.0122 \\
\hline 21 & 0.9945 & -0.0364 & 1.0309 & 1.0474 & 0.8928 & 1.0729 & 0.8772 & 1.0729 \\
\hline 22 & 0.9069 & 0.0598 & 0.8471 & 0.8746 & 0.7211 & 0.8804 & 0.6909 & 0.8804 \\
\hline 23 & 0.9409 & 0.0223 & 0.9186 & 0.9395 & 0.8039 & 0.9554 & 0.7706 & 0.9554 \\
\hline 24 & 0.9606 & 0.0050 & 0.9555 & 0.9789 & 0.8474 & 0.9899 & 0.8025 & 0.9899 \\
\hline 25 & 0.9664 & -0.0013 & 0.9677 & 0.9938 & 0.8572 & 1.0026 & 0.8148 & 1.0026 \\
\hline 26 & 0.9952 & -0.0345 & 1.0297 & 1.0502 & 0.9123 & 1.0690 & 0.8744 & 1.0690 \\
\hline 27 & 1.0000 & -0.0360 & 1.0360 & 1.0562 & 0.9283 & 1.0719 & 0.8857 & 1.0719 \\
\hline 28 & 1.0000 & -0.0174 & 1.0174 & 1.0349 & 0.9194 & 1.0349 & 0.8661 & 1.0349 \\
\hline 29 & 0.9982 & -0.0380 & 1.0362 & 1.0572 & 0.9206 & 1.0761 & 0.8935 & 1.0761 \\
\hline 30 & 0.9028 & 0.0592 & 0.8435 & 0.8676 & 0.7206 & 0.8815 & 0.6863 & 0.8815 \\
\hline 31 & 1.0000 & -0.0117 & 1.0117 & 1.0233 & 0.9237 & 1.0233 & 0.8755 & 1.0233 \\
\hline 32 & 0.9659 & -0.0028 & 0.9687 & 0.9965 & 0.8481 & 1.0056 & 0.8110 & 1.0056 \\
\hline 33 & 1.0000 & 0.0000 & 1.0000 & 1.0000 & 1.0000 & 1.0000 & 0.9984 & 1.0000 \\
\hline 34 & 1.0000 & -0.0028 & 1.0028 & 1.0056 & 0.9560 & 1.0056 & 0.9054 & 1.0056 \\
\hline 35 & 0.8007 & 0.1601 & 0.6406 & 0.6602 & 0.5244 & 0.6798 & 0.4868 & 0.6798 \\
\hline 36 & 0.9586 & -0.0008 & 0.9594 & 0.9784 & 0.8386 & 1.0015 & 0.8126 & 1.0015 \\
\hline 37 & 0.9047 & 0.0640 & 0.8407 & 0.8691 & 0.7246 & 0.8720 & 0.6863 & 0.8720 \\
\hline 38 & 0.9505 & 0.0132 & 0.9373 & 0.9627 & 0.8276 & 0.9736 & 0.7919 & 0.9736 \\
\hline 39 & 1.0000 & -0.0184 & 1.0184 & 1.0368 & 0.9203 & 1.0368 & 0.8623 & 1.0368 \\
\hline 40 & 0.9259 & 0.0339 & 0.8921 & 0.9103 & 0.7858 & 0.9323 & 0.7447 & 0.9323 \\
\hline 41 & 0.8703 & 0.0889 & 0.7814 & 0.8005 & 0.6649 & 0.8222 & 0.6268 & 0.8222 \\
\hline 42 & 0.9247 & 0.0363 & 0.8885 & 0.9090 & 0.7650 & 0.9274 & 0.7390 & 0.9274 \\
\hline 43 & 1.0000 & -0.0377 & 1.0377 & 1.0584 & 0.9261 & 1.0754 & 0.8913 & 1.0754 \\
\hline 44 & 0.8755 & 0.0838 & 0.7916 & 0.8100 & 0.6769 & 0.8323 & 0.6434 & 0.8323 \\
\hline 45 & 1.0000 & -0.0167 & 1.0167 & 1.0335 & 0.9275 & 1.0335 & 0.8574 & 1.0335 \\
\hline 46 & 0.8866 & 0.0844 & 0.8022 & 0.8305 & 0.7043 & 0.8312 & 0.6473 & 0.8312 \\
\hline 47 & 0.8862 & 0.0737 & 0.8125 & 0.8322 & 0.6977 & 0.8526 & 0.6628 & 0.8526 \\
\hline 48 & 0.8923 & 0.0715 & 0.8208 & 0.8476 & 0.7063 & 0.8571 & 0.6687 & 0.8571 \\
\hline 49 & 1.0000 & -0.0367 & 1.0367 & 1.0582 & 0.9354 & 1.0734 & 0.8863 & 1.0734 \\
\hline 50 & 1.0000 & -0.0331 & 1.0331 & 1.0576 & 0.9251 & 1.0662 & 0.8874 & 1.0662 \\
\hline
\end{tabular}

Table 8: Productive efficiency in Spanish banks, 1992-98

\begin{tabular}{cccc}
\hline \hline & Mean & Maximum (\#) & Minimum \\
\hline 1992 & 0.9313 & $1.000(14 / 50)$ & 0.7764 \\
1993 & 0.9264 & $1.000(16 / 50)$ & 0.7754 \\
1994 & 0.9361 & $1.000(13 / 50)$ & 0.8045 \\
1995 & 0.9326 & $1.000(13 / 50)$ & 0.7631 \\
1996 & 0.9442 & $1.000(18 / 50)$ & 0.8124 \\
1997 & 0.9465 & $1.000(17 / 50)$ & 0.7910 \\
1998 & 0.9501 & $1.000(17 / 50)$ & 0.8007 \\
\hline \hline
\end{tabular}


For years 1995 and 1998 (tables 6 and 7) we also have results on whether firms' efficiency improves or deteriorates. However, we should stress that, over time, there are fewer firms for which bias-corrected efficiency is substantially lower - in 1998, there are only 2 firms (\#13, 35) for which efficiency worsens by more than 0.1 .

However, to properly interpret the bias-corrected estimators $\tilde{\theta}_{i}$ in each table - particularly those larger than one - we must use information on confidence intervals, which define the statistical location of the true efficiency. Broadly, they show that efficiency scores, when adding statistical precision, overlap to a notable extent. For instance, in table 5, using the intervals in columns 5-6, we notice that firm \#2 overlaps with firms \#4, 8, or 10, amongst others, despite their differing bias-corrected efficiency estimates. On the other hand, firm \#2 does not overlap with firms \#3 or 11, for instance. This overlap occurs not only when the bias corrected intervals are considered but also when we consider the intervals centered on $\hat{\theta}_{i}$ (columns 7-8). Therefore, in many instances there is no enough empirical evidence to reject the hypothesis that two firms are equally efficient. Consequently, as stated by Simar and Wilson (1998), we should be particularly cautious when making relative comparisons of the performances among firms based on the original efficiency scores $\hat{\theta}_{i}$. In our particular case, results show that disparities are much wider when the bootstrap analysis is performed.

However, further information is available. Figure 3 contains box plots which disclose information about the distributions of each firm's pseudo sample. The main advantage of this representation is that when simultaneously displaying several box plots, it is easier to see whether differences exist both between firms and for the same firm over time. Examples are the existence, emergence, or vanishing of outliers, dispersion or concentration of data, or the symmetry (or asymmetry) of the distribution.

The vertical axis of each sub-figure 3.a-3.c represents the variable's scale. The box represents the interquartile range (IQR). The 0.75 and 0.25 quartiles $\left(\xi_{.75}\right.$ and $\left.\xi_{.25}\right)$, define the upper and lower segments, respectively. $50 \%$ of the distribution of probability mass is inside the box. Thus, its height represents the IQR, a usual dispersion measure. A small IQR is small results in a short box, revealing that $50 \%$ of the density is fairly concentrated. The horizontal line inside the box is the median, or 0.50 quartile. Its location relative to the upper or lower limits of the box provides graphical information about the shape of the distribution. If it is not in the center of the box, the distribution is asymmetric. Two vertical lines are shown in the upper and lower limits of the box. The end of each line is known as the adjacent value (whisker), either upper or lower. In fact, the maximum distance between whiskers is given by the $\left[\xi_{.25}-1.5 R\left(\xi_{.25}\right), \xi_{.75}+1.5 R\left(\xi_{.25}\right)\right]$ interval, where $R\left(\xi_{.25}\right)$ is the IQR. Therefore, the whiskers define the natural bounds of the distributions, and the crosses represent outliers lying outside them.

Figure 3 indicates how sensitive a particular firm's efficiency score is to variations in the efficiency of other firms in the data set. For instance, firm \#1 in 1992 has an original efficiency score of $\hat{\theta}_{i}=1$; figure 3.a shows that it is ostensibly efficient. The box above unity does not mean we get efficiency scores above unity - which may not occur. As suggested earlier in the paper, those bootstrapped values above unity should be treated as 1 . There are firms for which this occurs to a greater extent. For example, all bootstrapped efficiency scores for firm \#6 in 1992 are 1, as shown by a single point in figure 3.a, with no box and no whiskers. In other words, we have probability mass degenerated at 1. 
Figure 3: Box plots of firms' efficiencies, years 1992, 1995, 1998

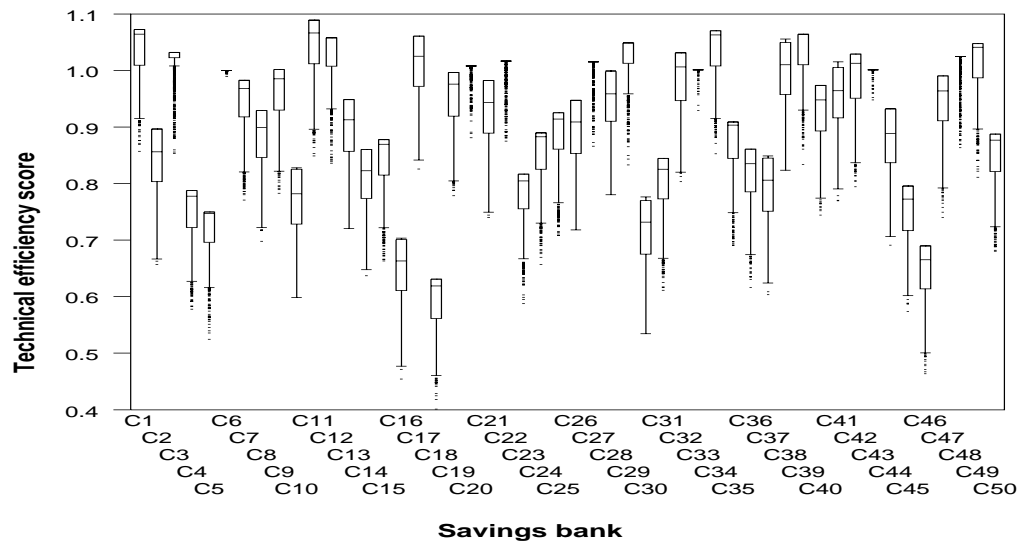

a) 1992

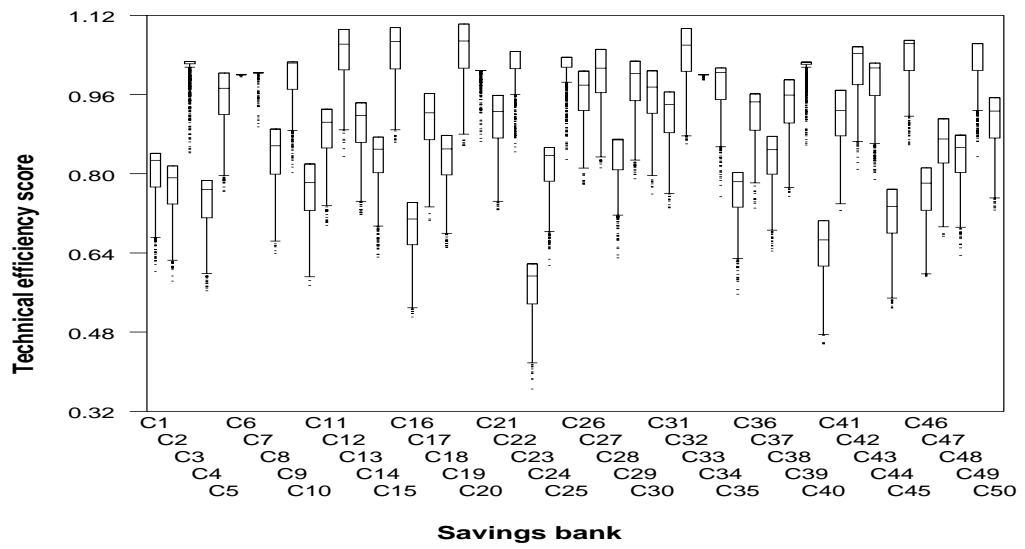

b) 1995

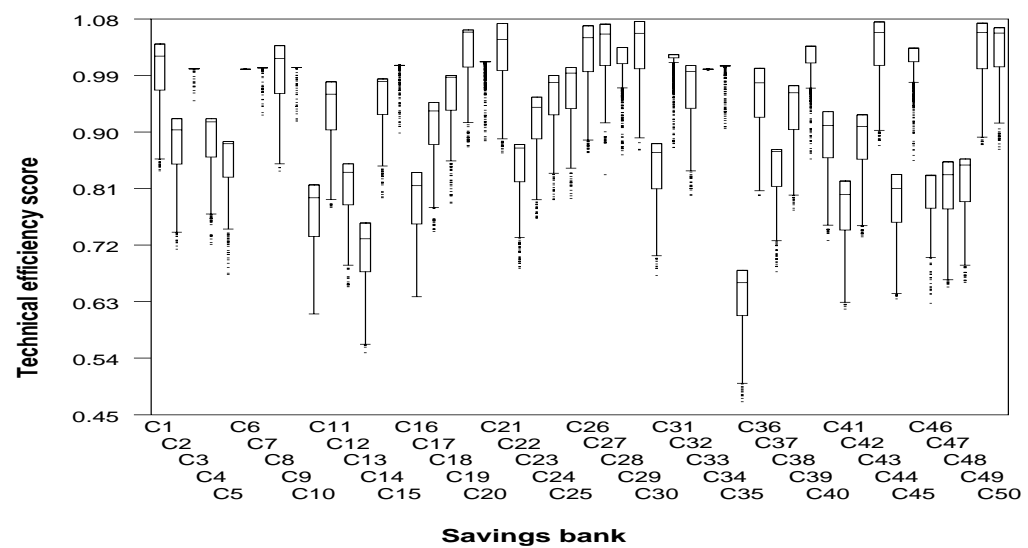

c) 1998 


\section{Conclusions}

This paper has applied recently devised approaches to bootstrapping both Malmquist productivity indices and efficiency scores to a database of Spanish savings banks over the initial 1992-1998 post-deregulation period. Although results on the two issues overlap to a great extent, we will summarize them separately.

With regard to productivity indices, the picture that emerges is one of productivity growth due to an improvement of production possibilities. Only the firms lagging behind the efficient frontier lessen such growth. This occurs due to the technical progress which took place at particularly high rate in 1992/93, 1996/97 and 1997/98. As a result, on average, firms are able to provide $119 \%$ as much service per unit of resource consumed as they were providing just six years earlier.

The bootstrap allows for a more careful analysis of what happens at firm level. Specifically, the original results show that, over the entire period (1992/98), about $90 \%$ of firms grew in terms of productivity. However, not every firm had Malmquist productivity indices significantly different from unity at $5 \%$. In contrast, only $10 \%$ of firms suffered productivity decline, and in all cases it was statistically significant at $5 \%$. Therefore, the bootstrap backs up the conclusions provided by the original indices. A similar pattern is observed in the technical change component. In this case, only two firms experienced technological regress which, in addition, was significant in just one case (and at the $10 \%$ significance level). We can thus verify that productivity regress is due mainly to declines in efficiency.

Concerning efficiency scores, the contribution of the bootstrap is similar. Specifically, mean technical efficiency is quite high, and does not vary greatly over the sample period. However, it seems that there are substantial disparities between firms but, at the same time, some firms have more similar efficiencies than what was suggested by the "original" efficiency scores, and vice versa.

These results are coincidental with what might a priori be expected in a context of deregulation. They are similar to those obtained by Mukherjee et al. (2001), Gilbert and Wilson (1998) or Berg et al. (1992b). However, they run counter to Wheelock and Wilson (1999) - although they consider a different Malmquist productivity index decomposition. If we consider the Spanish experience, our results are coincidental with those obtained by Pastor (1995), but differ from those obtained by Grifell-Tatjé and Lovell (1996). The latter, however, is not paradoxical, as their choice of outputs differs from ours, and, of particular importance, their sample period is also different.

The reasons underlying these trends may arise from different sources. Productivity growth could partly come from the difficulties affecting many savings banks engaged in M\&As. New firms were created, and some of them had branches which were concentrated too locally. After closing down the geographically closest branches, efficiency and productivity gains might have been substantial. Other firms engaged in rapid geographic expansion. There has also been a dramatic boom in mutual funds to the detriment of deposits; their loss may have not been offset by the increase in fee-income, which is accounted for in our definition of outputs.

In a further study, we will explore these details more deeply, to find out not only which firms experience faster productivity growth, but also which undergo stronger sampling variation, and what might determine this. Another more technically arduous stem of research should attempt to address the problem of 
bootstrapping cost and, possibly, profit and revenue efficiency scores. This is especially relevant in banking where, in contrast to public sector studies, prices are usually available.

All computations were performed using MATLAB code written by the authors. For bootstrapping technical efficiency scores we had additional problems, as it requires univariate nonparametric density estimation and, consequently, a bandwidth choice. Plug-in rules, which seem to be reasonably reliable in terms of a fair balance between bias and variance, are provided in Sheather and Jones (1991). Their MATLAB code (bwsjpiSM.m) is available through URL:http://www.stat.unc.edu/faculty/marron.html. We easily incorporated this code into ours. However, in the case of Malmquist productivity indices we have panel data which requires bivariate density estimation. This was also performed via kernel smoothing. In this case the state of the art does not provide such satisfactory bandwidths as those for the univariate case. Wand and Jones (1994) provide plug-in methods, although they are somewhat difficult to implement in MATLAB, as they are originally written in S-PLUS. ${ }^{17}$ We therefore used those suggested by Simar and Wilson (1999a). We do however recognize that there is still room for improvement on this matter.

\section{References}

Banker, R. D. (1993). Maximum likelihood, consistency and Data Envelopment Analysis: A statistical foundation. Management Science, 39(10):1265-1273.

Banker, R. D. (1996). Hypothesis tests using data envelopment analysis. Journal of Productivity Analysis, $7: 139-159$.

Bauer, P. W., Berger, A. N., and Humphrey, D. B. (1993). Efficiency and productivity growth in U.S. banking. In Fried, H. O., Lovell, C. A. K., and Schmidt, S. S., editors, The Measurement of Productive Efficiency: Techniques and Applications, pages 386-413. Oxford University Press, Oxford.

Berg, S. A., Førsund, F. R., and Jansen, E. S. (1992a). Malmquist indices of productivity growth during the deregulation of Norwegian banking, 1980-89. Scandinavian Journal of Economics, 94, Supplement:211228 .

Berg, S. A., Førsund, F. R., and Jansen, E. S. (1992b). Technical efficiency of Norwegian banks: The non-parametric approach to efficiency measurement. The Journal of Productivity Analysis, 2:127-142.

Berger, A. N. and Humphrey, D. B. (1997). Efficiency of financial institutions: International survey and directions for future research. European Journal of Operational Research, 98:175-212.

Caves, D. W., Christensen, L. R., and Diewert, W. E. (1982). The economic theory of index numbers and the measurement of input, output, and productivity. Econometrica, 50(6):1393-1414.

Danthine, J.-P., Giavazzi, F., Vives, X., and von Thadden, E.-L. (1999). The Future of European Banking, volume 9 of Monitoring European Integration. Center for Economic Policy Research, London.

\footnotetext{
${ }^{17}$ They are available through URL:http://www. biostat.harvard.edu/ mwand/software.html.
} 
Efron, B. (1979). Bootstrap methods: Another look at the Jacknife. Annals of Statistics, 7:1-26.

Efron, B. and Tibshirani, R. J. (1993). An Introduction to the Bootstrap. Chapman and Hall, London.

European Central Bank (2000). EU banks' income structure. Other publications, European Central Bank, Frankfurt am Main, Germany.

Färe, R., Grosskopf, S., Lindgren, B., and Roos, P. (1992). Productivity change in Swedish pharmacies 1980-1989: A non-parametric Malmquist approach. Journal of Productivity Analysis, 3:85-101.

Färe, R., Grosskopf, S., Norris, M., and Zhang, Z. (1994). Productivity growth, technical progress, and efficiency change in industrialized countries. American Economic Review, 84(1):66-83.

Färe, R., Grosskopf, S., and Weber, W. L. (1989). Measuring school district performance. Public Finance Quarterly, 17(4):409-429.

Färe, R. and Whittaker, G. (1995). An intermediate input model of dairy production using complex survey data. Journal of Agricultural Economics, 46(2):201-213.

Farrell, M. J. (1957). The measurement of productive efficiency. Journal of the Royal Statistical Society, Ser.A,120:253-281.

Ferrier, G. D., Grosskopf, S., Hayes, K. J., and Yaisawarng, S. (1993). Economies of diversification in the banking industry: A frontier approach. Journal of Monetary Economics, 31:229-249.

Ferrier, G. D. and Hirschberg, J. D. (1997). Bootstrapping confidence intervals for linear programming efficiency scores: With an illustration using Italian banking data. Journal of Productivity Analysis, $8: 19-33$.

Ferrier, G. D. and Hirschberg, J. G. (1999). Can we bootstrap DEA scores? Journal of Productivity Analysis, 11:81-92.

Freixas, X. and Santomero, A. M. (2002). An overall perspective on banking regulation. In Boot, A., Bhattacharya, S., and Thakor, A., editors, Financial Regulation. Oxford University Press, Oxford.

Gilbert, R. A. and Wilson, P. W. (1998). Effects of deregulation on the productivity of Korean banks. Journal of Economics and Business, 50:133-155.

González, X. M. and Miles, D. (2002). Statistical precision of DEA: A bootstrap application to Spanish public services. Applied Economics Letters, 9:127-132.

Gorton, G. and Rosen, R. (1995). Corporate control, portfolio choice, and the decline in banking. Journal of Finance, 50:1377-1419.

Grifell-Tatjé, E. and Lovell, C. A. K. (1995a). Estrategias de gestión y cambio productivo en el sector bancario español. Papeles de Economía Española, 65:174-184. 
Grifell-Tatjé, E. and Lovell, C. A. K. (1995b). A note on the Malmquist productivity index. Economics Letters, 47:169-175.

Grifell-Tatjé, E. and Lovell, C. A. K. (1996). Deregulation and productivity decline: The case of Spanish savings banks. European Economic Review, 40(6):1281-1303.

Grifell-Tatjé, E. and Lovell, C. A. K. (1997). The sources of productivity change in Spanish banking. European Journal of Operational Research, 98:365-381.

Grosskopf, S. (1993). Efficiency and productivity. In Fried, H. O., Lovell, C. A. K., and Schmidt, S. S., editors, The Measurement of Productive Efficiency: Techniques and Applications, pages 161-193. Oxford University Press, Oxford.

Grosskopf, S. (1996). Statistical inference and nonparametric efficiency: A selective survey. Journal of Productivity Analysis, 7:161-176.

Grosskopf, S. and Yaisawarng, S. (1990). Economies of scope in the provision of local public services. National Tax Journal, 43:61-74

Horowitz, J. L. (1997). Bootstrap methods in econometrics: Theory and numerical performance. In Krepps, D. M. and Wallis, K. F., editors, Advances in Economics and Econometrics: Theory and Applications, volume 3, pages 188-222. Cambridge University Press.

Horowitz, J. L. (2001a). The bootstrap. In Heckman, J. J. and Leamer, E. E., editors, Handbook of Econometrics, volume 5, chapter 52. Nort-Holland, Amsterdam.

Horowitz, J. L. (2001b). The bootstrap and hypothesis tests in econometrics. Journal of Econometrics, 100:37-40.

Humphrey, D. B. (1993). Cost and technical change: Effects from bank deregulation. Journal of Productivity Analysis, 4:9-34.

Kumbhakar, S. C., Lozano-Vivas, A., Lovell, C. A. K., and Hasan, I. (2001). The effects of deregulation on the performance of financial institutions: The case of Spanish savings banks. Journal of Money, Credit, and Banking, 33(1):101-120.

Lovell, C. A. K. (2000). Editor's introduction. Journal of Productivity Analysis, 13:5-6.

Malmquist, S. (1953). Index numbers and indifference surfaces. Trabajos de Estadística, 4:209-242.

Mooney, C. Z. and Duval, R. D. (1993). Bootstrapping. A Nonparametric Approach to Statistical Inference, volume 07-095 of Sage University Paper series on Quantitative Applications in the Social Sciences. Sage Publications, Newbury Park, California.

Mukherjee, K., Ray, S. C., and Miller, S. M. (2001). Productivity growth in large US commercial banks: The initial post-deregulation experience. Journal of Banking and Finance, 25:913-939. 
Pastor, J. M. (1995). Eficiencia, cambio productivo y cambio técnico en los bancos y cajas de ahorro españolas: un análisis de la frontera no paramétrico. Revista Española de Economía, 12(1):35-73.

Raymond, J. L. and García Greciano, B. (1994). Las disparidades en el PIB per cápita entre Comunidades Autónomas y la hipótesis de convergencia. Papeles de Economía Española, 59:37-58.

Rogers, K. E. (1998). Nontraditional activities and the efficiency of U.S. commercial banks. Journal of Banking and Finance, 22:467-482.

Rogers, K. E. and Sinkey Jr, J. F. (1999). An analysis of nontraditional activities at U.S. commercial banks. Review of Financial Economics, 8:25-39.

Sheather, S. J. and Jones, M. C. (1991). A reliable data-based bandwidth selection method for kernel density estimation. Journal of the Royal Statistical Society, Ser.B,53(3):683-690.

Shephard, R. W. (1970). Theory of Cost and Production Functions. Princeton University Press, Princeton.

Silverman, B. W. (1986). Density Estimation for Statistics and Data Analysis. Chapman and Hall, London.

Simar, L. and Wilson, P. W. (1998). Sensitivity analysis of efficiency scores: How to bootstrap in nonparametric frontier models. Management Science, 44(1):49-61.

Simar, L. and Wilson, P. W. (1999a). Estimating and bootstrapping Malmquist indices. European Journal of Operational Research, 115:459-471.

Simar, L. and Wilson, P. W. (1999b). Of course we can bootstrap DEA scores! But does it mean anything? Logic trumps wishful thinking. Journal of Productivity Analysis, 11:93-97.

Simar, L. and Wilson, P. W. (1999c). Some problems with the Ferrier/Hirschberg bootstrap idea. Journal of Productivity Analysis, 11:67-80.

Simar, L. and Wilson, P. W. (2000). Statistical inference in nonparametric frontier models: The state of the art. Journal of Productivity Analysis, 13(1):49-78.

Tortosa-Ausina, E. (2002a). Bank cost efficiency and output specification. Journal of Productivity Analysis, 18(3):199-222.

Tortosa-Ausina, E. (2002b). Financial costs, operating costs, and specialization of Spanish banking firms as distribution dynamics. Applied Economics, forthcoming.

Wand, M. P. and Jones, M. C. (1994). Multivariate plug-in bandwidth selection. Computational Statistics, 9:97-116.

Wheelock, D. C. and Wilson, P. W. (1999). Technical progress, inefficiency, and productivity change in US banking, 1984-1993. Journal of Money, Credit, and Banking, 31(2):212-234. 